\title{
Thermal Properties of Structural Materials Found in Light Water Reactor Vessels
}

\author{
J. E. Daw \\ J. L. Rempe \\ D. L. Knudson
}

November 2009

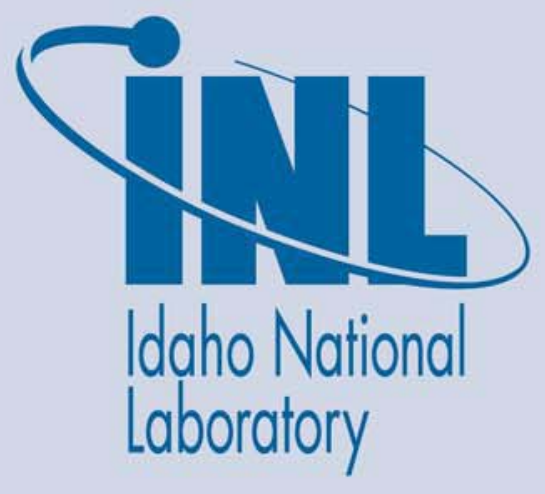

The INL is a U.S. Department of Energy National Laboratory operated by Battelle Energy Alliance 


\title{
Thermal Properties of Structural Materials Found in Light Water Reactor Vessels
}

\author{
J. E. Daw \\ J. L. Rempe \\ D. L. Knudson
}

November 2009

Idaho National Laboratory

Idaho Falls, Idaho 83415

http://www.inl.gov

\author{
Prepared for the \\ U.S. Department of Energy \\ Office of Nuclear Energy \\ Under DOE Idaho Operations Office \\ Contract DE-AC07-05ID14517
}


INL/EXT-09-16121 


\section{CONTENTS}

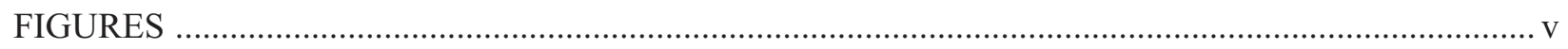

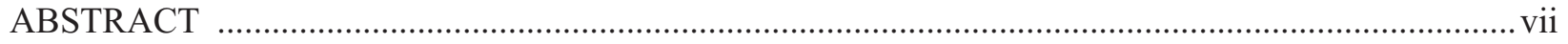

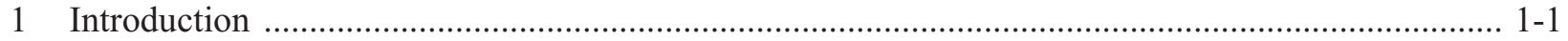

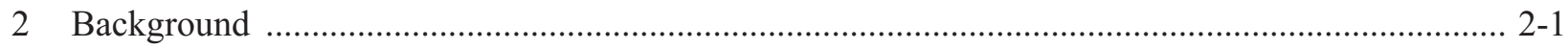

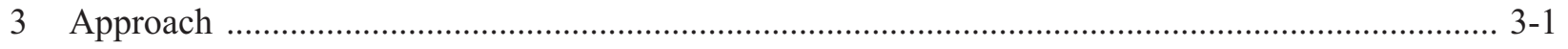

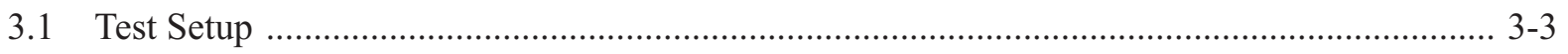

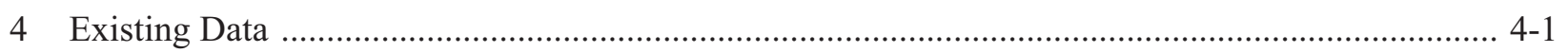

4.1 SA533-B1 Low Alloy Steel ....................................................................................... 4-1

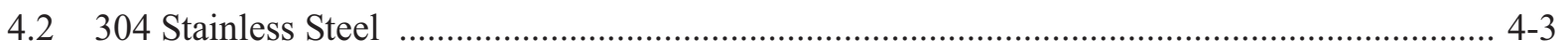

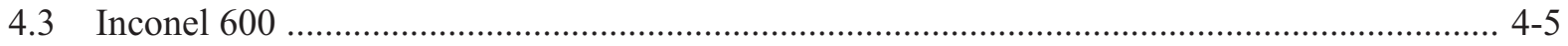

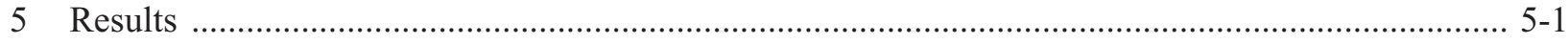

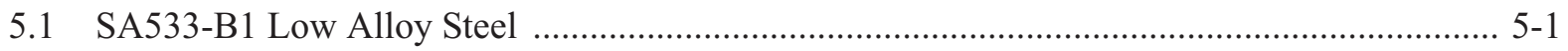

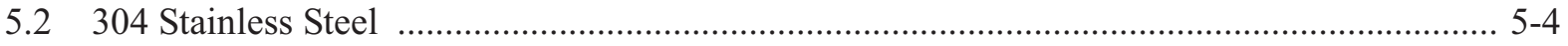

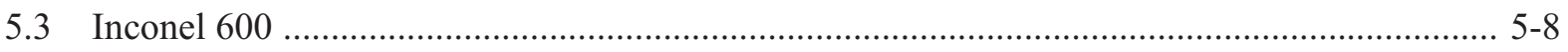

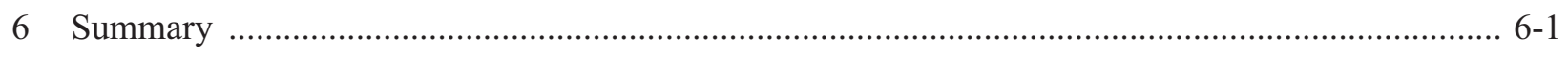

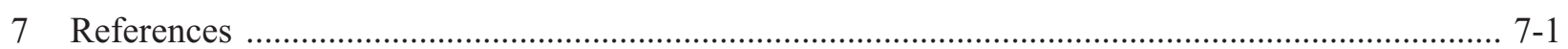


INL/LTD-09-09-16121 


\section{FIGURES}

3-1. Schematic diagram of DSC furnace and sample carrier. ....................................................... 3-2

3-2. Laser Flash thermal diffusivity measurement method......................................................... 3-2

3-3. Dilatometer and calorimeter measurement systems.......................................................... 3-4

3-4. Laser Flash thermal property analyzer................................................................................ 3-4

4-1. Literature values for SA533 density. ................................................................................ 4-1

4-2. Literature values for SA533 specific heat capacity .............................................................. 4-2

4-3. Literature values for SA 533 thermal diffusivity. ............................................................ 4-2

4-4. Literature values for SA533 thermal conductivity. ............................................................. 4-3

4-5. Literature values for SS304 density. ..................................................................................... 4-4

4-6. Literature values for SS304 specific heat capacity............................................................... 4-4

4-7. Literature values for SS304 thermal diffusivity ................................................................... 4-5

4-8. Literature values for SS304 thermal conductivity. ............................................................. 4-6

4-9. Literature values for Inconel 600 density............................................................................. 4-6

4-10. Literature values for Inconel 600 specific heat capacity...................................................... 4-7

4-11. Literature values for Inconel 600 thermal conductivity........................................................ 4-8

5-1. Comparison of INL SA533 thermal expansion data with literature sources. ............................ 5-1

5-2. Comparison of INL SA533 density data with literature sources. .............................................. 5-2

5-3. Comparison of INL SA533 specific heat capacity data with literature sources. ...................... 5-3

5-4. $\quad$ SA 533 specific heat capacity curve with estimated phase change temperatures and enthalpy change as calculated using Netzsch software. ...................................................... 5-3

5-5. Comparison of INL SA533 thermal diffusivity data with literature sources............................. 5-4

5-6. Comparison of INL SA533 thermal conductivity data with literature sources......................... 5-5

5-7. Comparison of INL SS 304 thermal expansion data with literature sources............................. 5-5

5-8. Comparison of INL SS 304 density data with literature sources........................................ 5-6

5-9. Comparison of INL SA533 specific heat capacity data with literature sources. ........................ 5-7

5-10. Comparison of INL SA533 thermal diffusivity data with literature sources............................. 5-7

5-11. Comparison of INL SA533 thermal conductivity data with literature sources.......................... 5-8

5-12. Comparison of INL Inconel 600 thermal expansion data with literature sources....................... 5-9

5-13. Comparison of INL Inconel 600 density data with literature values. ....................................... 5-9

5-14. Comparison of INL Inconel 600 specific heat capacity data with literature sources................ 5-10

5-15. INL Inconel 600 thermal diffusivity data............................................................................ 5-11

5-16. Comparison of INL Inconel 600 thermal conductivity data with literature sources................. 5-11 
INL/EXT-09-16121 


\begin{abstract}
High temperature material property data for structural materials used in existing Light Water Reactors (LWRs) are limited. Often, extrapolated values recommended in the literature differ significantly. To reduce such uncertainties, new data for SA533 Grade B, Class 1 (SA533B1) low alloy steel, Stainless Steel 304 (SS304), and Inconel 600, found in Light Water Reactor (LWR) vessels and penetrations, were acquired and tested using material property systems available at the High Temperature Test Laboratory (HTTL) at the Idaho National Laboratory (INL). Properties measured include thermal expansion, specific heat capacity, and thermal diffusivity for temperatures up to $1200{ }^{\circ} \mathrm{C}$. From these results, thermal conductivity and density were calculated. Results show that, in some cases, previously recommended values for these material differ significantly from measured values at high temperatures. This is especially true for SA533B1, as previous data do not account for the phase transformation of this material between $740{ }^{\circ} \mathrm{C}$ and $840{ }^{\circ} \mathrm{C}$.
\end{abstract}


INL/EXT-09-16121 


\section{Introduction}

High temperature thermal property data for structural materials used in Light Water Reactors (LWRs) are limited. A literature review revealed that high temperature properties are extrapolated with little data above $700{ }^{\circ} \mathrm{C}$ for these materials. To address this need, three methods of obtaining thermal material properties available at Idaho National Laboratory's (INL's) High Temperature Test Laboratory (HTTL) were applied to measure thermal expansion, thermal diffusivity, and specific heat capacity. Results of these tests were then used to calculate thermal

conductivity and density. Results are compared with data in the literature and with data for other structural and penetration materials typically found in LWR vessels, Inconel 600, Stainless Steel 304 (SS304) and SA533-B1 low alloy carbon steel. 
INL/EXT-09-16121 


\section{Background}

Because of the impact that melt relocation and vessel failure have on subsequent progression and associated consequences of a LWR accident, it is important to accurately predict the heat-up and relocation of materials within the reactor vessel and heat transfer to and from the reactor vessel. Accurate predictions of such heat transfer phenomena require high temperature thermal properties. However, a review of vessel and structural steel material properties in severe accident analysis codes reveals that the required high temperature material properties are extrapolated with little, if any, data above $700 \mathrm{C}$.

Thermal conductivity data for SS304 and SA533-B1 were previously collected at the HTTL using the transient pulsed method ${ }^{1,2}$. These data were used in conjunction with a ratio technique to calculate the specific heat of samples. The current work utilizes a DSC to more accurately measure the specific heat. Further, the current study is expanded to include Incone 600. Data previously obtained using the pulsed method are provided for comparison to data found in commonly used references as well as data collected in the current research effort. Some data used in this analysis (thermal elongation of SS304 and SA533-B1) were collected and reported previously $^{3,4}$. 
INL/EXT-09-16121 


\section{Approach}

Material property data were collected for each material using equipment available at the HTTL. This equipment includes a Netzsch 402 ES pushrod dilatometer ${ }^{4}$, a Netzsch 404 DSC differential scanning calorimeter ${ }^{5}$, and an Anter FL 5000 Laser Flash thermal property analyzer ${ }^{6}$.

Thermal expansion (changes in length caused by changes in temperature) of the test materials was measured using the dilatometer. This is accomplished by heating the sample in an accurately controlled furnace, and measuring the deflection caused by thermal expansion using a linear variable differential transformer (LVDT). Before an experimental sample may be tested, a standard must be tested (accuracy is improved when sample and reference room temperature lengths are similar). This allows for compensation of the thermal characteristics of the system (expansion of system components such as the pushrod and sample carrier) by a software ${ }^{7}$ program provided by the manufacturer. After correcting (done automatically by software) for the expansion of system components, the raw data are quantified as thermal expansion as a function of temperature. The thermal expansion coefficient may also be automatically derived using the software. Assuming that the material is isotropic, the density, $\rho$, of the material as a function of temperature may be calculated using the equation:

$$
\rho=\frac{\rho_{o}}{1+3 \frac{\Delta l}{l_{o}}}
$$

where $\rho_{o}$ represents the room temperature density, $\Delta l$ represents the change in length, and $l_{o}$ represents the total sample length at room temperature.

The differential scanning calorimeter (DSC) allows for the measurement of specific heat capacity. The DSC utilizes a comparative analysis to determine the specific heat of an experimental sample as a ratio of the specific heat of a reference sample. Figure 3-1 shows a schematic diagram of the DSC. Reference (always left empty) and sample crucibles are placed on a sample carrier within a furnace of cylindric geometry which generates heat radially toward the center. Temperature is detected by thermocouples in contact with each crucible. One thermoelement is shared between the crucibles allowing the temperature difference to be measured as a voltage (converted to a specific heat value using the reference material data). Because the analysis is comparative, three tests must be run for each specimen. The first test is run without a sample installed in the sample crucible. This test allows for compensation of the thermal behavior of system components. The second test is performed with a reference sample of well defined specific heat capacity installed in the sample crucible (accuracy is improved when the experimental and reference sample masses are very close). The final test is performed with the experimental sample installed in the sample crucible. The software ${ }^{7}$ provided with the DSC automatically compensates for the system characteristics and calculates the specific heat of the experimental sample as a ratio of the specific heat of the reference sample. 


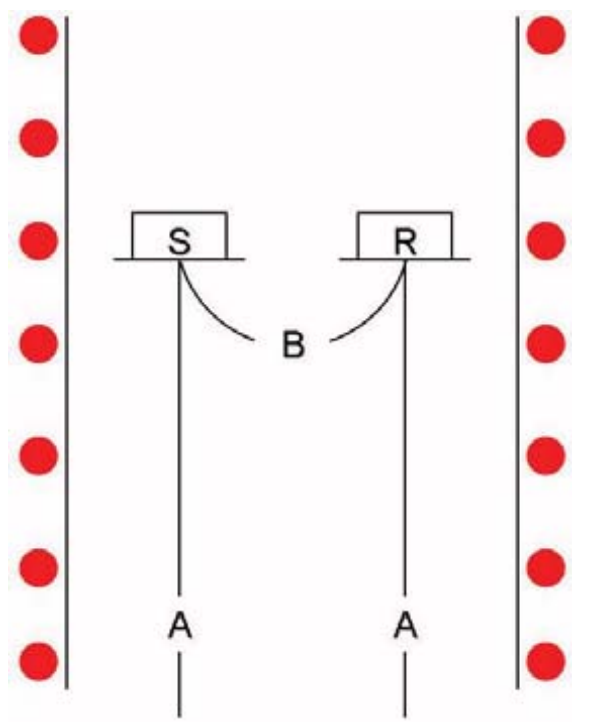

Figure 3-1. Schematic diagram of DSC furnace and sample carrier.

Thermal diffusivity data were collected using the LaserFlash Thermal Property Analyzer. The laser flash measurement method, shown in Figure 3-2(a), exposes one face of a thin (manufacturer recommendation is $2 \mathrm{~mm}$ for metallic samples), uniform sample to an instantaneous energy pulse (typically from a laser). The thermal diffusivity can be calculated from the maximum temperature the opposite face reaches and the time required to reach half the value of this temperature or the 'half max time,' shown in Figure 3-2(b).

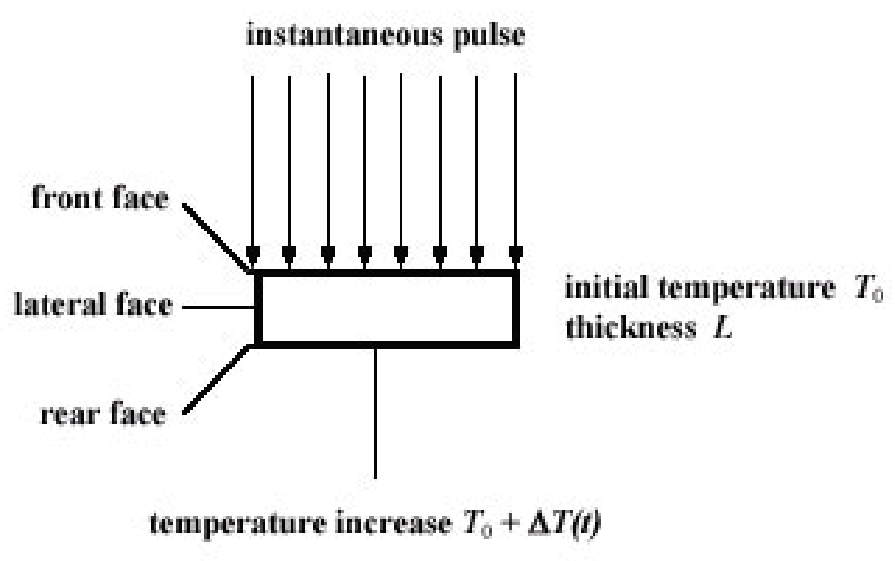

(a)

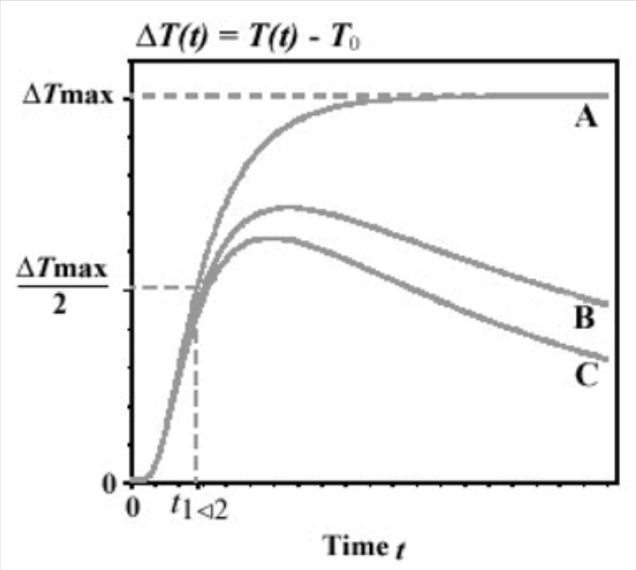

(b)

Figure 3-2. Laser Flash thermal diffusivity measurement method.

The flash method invokes certain ideal assumptions that are unattainable in practical application. For example, the energy pulse duration may be very short, but is not instantaneous; some laser energy may be reflected (samples were sprayed with a graphite layer to reduce reflectivity); sample thickness and surface condition are not truly uniform; and heat losses are not 
negligible. Note, curve A represents an ideal case, with no energy losses, while curves B and C represent 'real world' cases where energy losses are present and corrected for via software. Therefore, a flash measurement system typically applies correction algorithms to improve the quality of results.

The ideal test case (instantaneous energy pulse, no heat losses, uniform material) was solved by Parker $^{8}$. Due to the non-ideal nature of real world testing, several correction algorithms are included in the Anter FL 5000 software package. Each algorithm is applied automatically during testing and may be displayed during analysis by opening the various results files that are produced. The default correction uses Clark and Taylor's ${ }^{9}$ algorithm.

Previous testing with the LaserFlash system ${ }^{1,2}$ indicates that adjustment of system parameters (i.e. laser voltage, sampling rate) has negligible effect on results. Therefore, all testing was performed using the default system settings.

Thermal conductivity is then found using the relation:

$k=\rho \cdot c_{p} \cdot \alpha$

where $\mathrm{k}$ represents thermal conductivity, $\rho$ represents the density, $c_{p}$ represents the specific heat capacity, and $\alpha$ represents the thermal diffusivity. Note that all quantities are temperature dependant.

\subsection{Test Setup}

Figure 3-3 shows the Netzsch DIL 402 ES dilatometer and 404 DSC differential scanning calorimeter measurement systems installed at INL's HTTL. The system consists of the dilatometer (which contains an LVDT, sample holder, and furnace), the DSC (which contains a sample holder with a differential thermocouple, and a furnace), the Thermal Analysis System Controller (TASC) which links the systems to a CPU, a furnace power source, a coolant circulator (not visible), a vacuum pump, and the CPU.

Figure 3-4 shows the Anter FL5000 Laser Flash thermal property analyzer installed at the HTTL. The system consists of two test furnaces (referred to as tungsten and alumina furnaces), a CPU, a vacuum pump, and a laser power source (behind the alumina furnace in the figure) with a fiber optic delivery system and an integrated cooling system. 


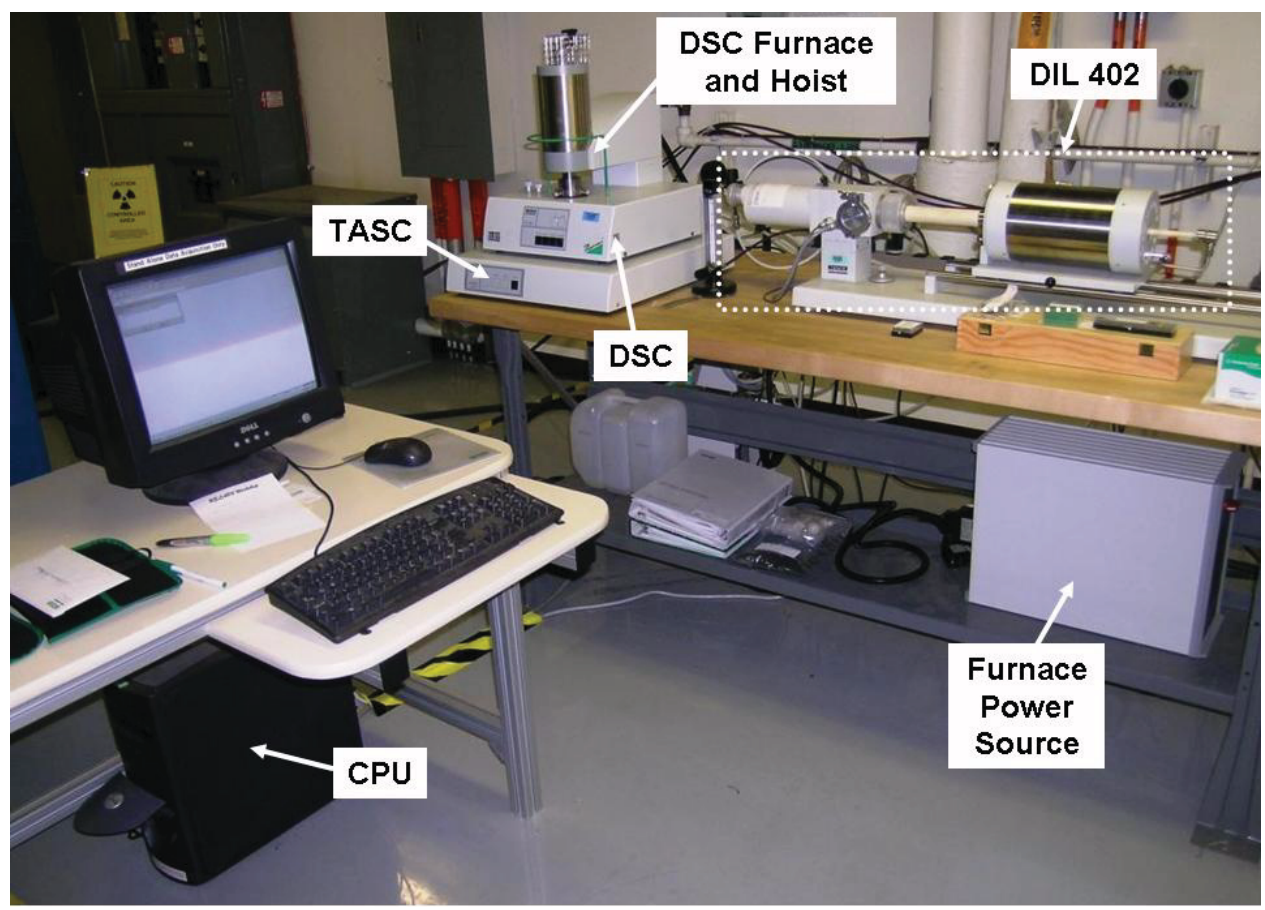

Figure 3-3. Dilatometer and calorimeter measurement systems.

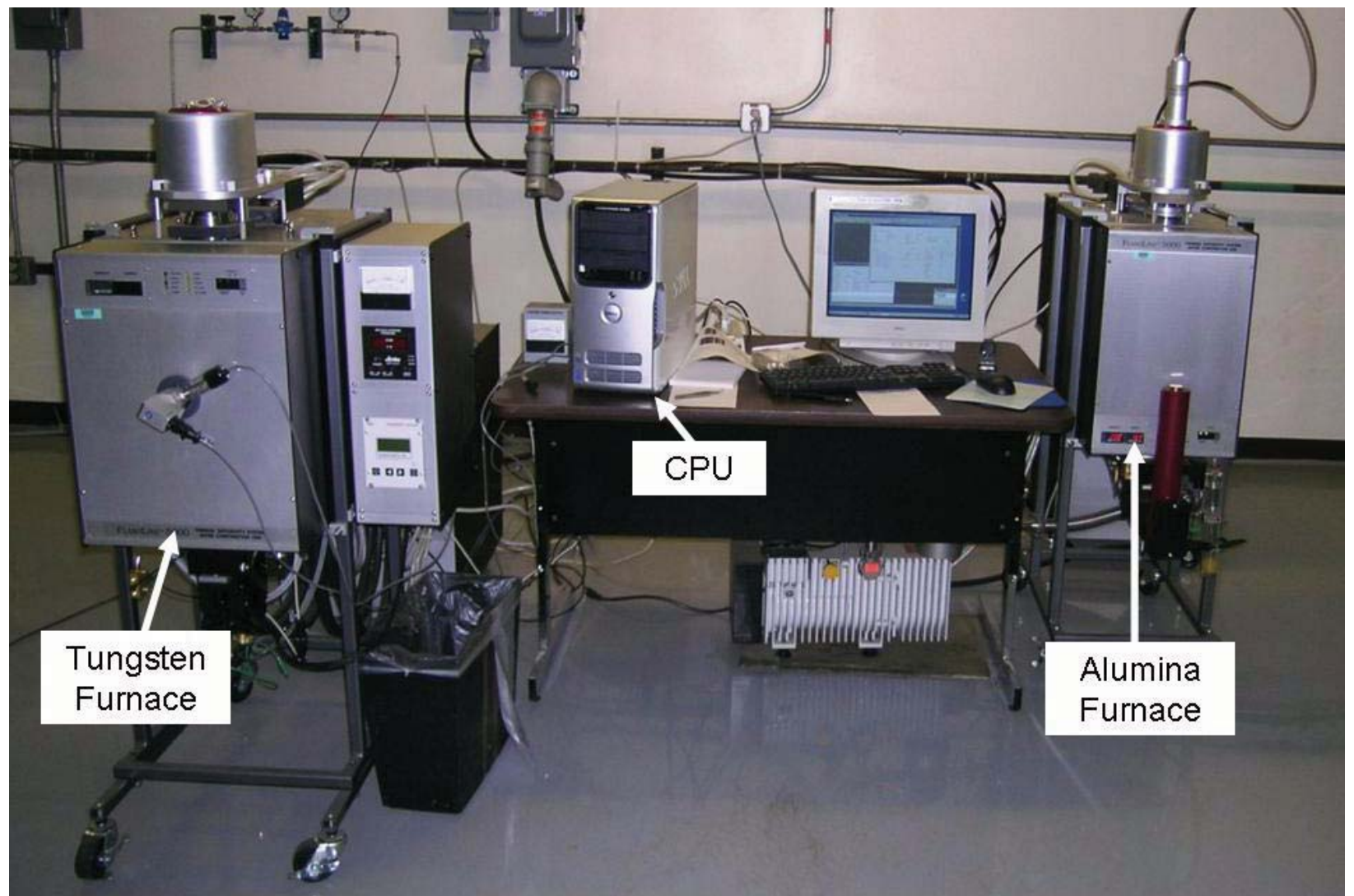

Figure 3-4. Laser Flash thermal property analyzer. 


\section{Existing Data}

The following subsections provide an overview of widely used material property data currently available in reference sources. The data shown are used for comparison to data acquired at the HTTL.

\subsection{SA533-B1 Low Alloy Steel}

Figures 4-1 through 4-4 show material property data found in the MATPRO library ${ }^{10}$. MATPRO is the material property data package used in the SCDAP/RELAP5-3D ${ }^{\odot}$ and MELCOR state-of-the-art severe accident analysis codes. MATPRO SA533 data are based on information from Spanner, et al. ${ }^{11}$ Also shown in these figures are density data from Neimark ${ }^{12}$, specific heat from Netzsch ${ }^{7}$ (an iron sample) and references [13]-[18] (cited as various in figures), and thermal conductivity data ${ }^{19,20}$. Note, MATPRO data for temperatures above $730{ }^{\circ} \mathrm{C}$ and all data plotted with dashed lines are extrapolated.

Figure 4-1 shows density data for SA533 steel. At the maximum temperature reported by Neimark, there is a difference of $0.8 \%\left(62.5 \mathrm{~kg} / \mathrm{m}^{3}\right)$ between the Neimark and MATPRO data. It should also be noted that neither source reports data above the lower bound of the ferritic to austenitic phase change (about $730^{\circ} \mathrm{C}$ ).

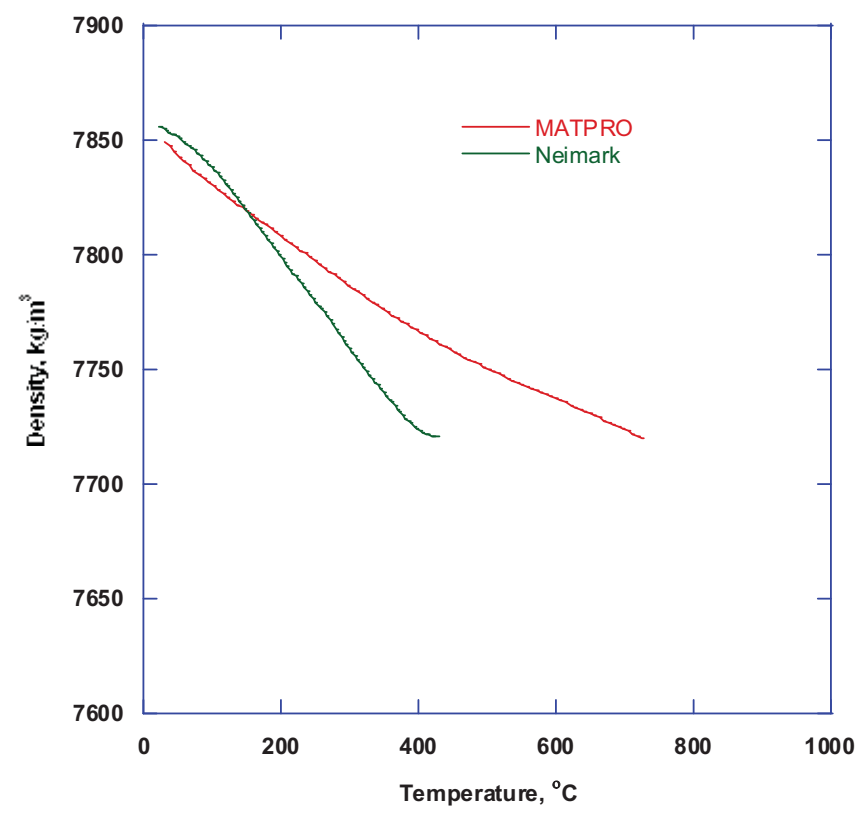

Figure 4-1. Literature values for SA533 density.

Figure 4-2 shows specific heat capacity data for SA533 steel. At the maximum (nonextrapolated) temperature limit, the data vary by $6 \%(56.2 \mathrm{~J} / \mathrm{kg} * \mathrm{~K})$. This does not include the Netzsch iron data. 


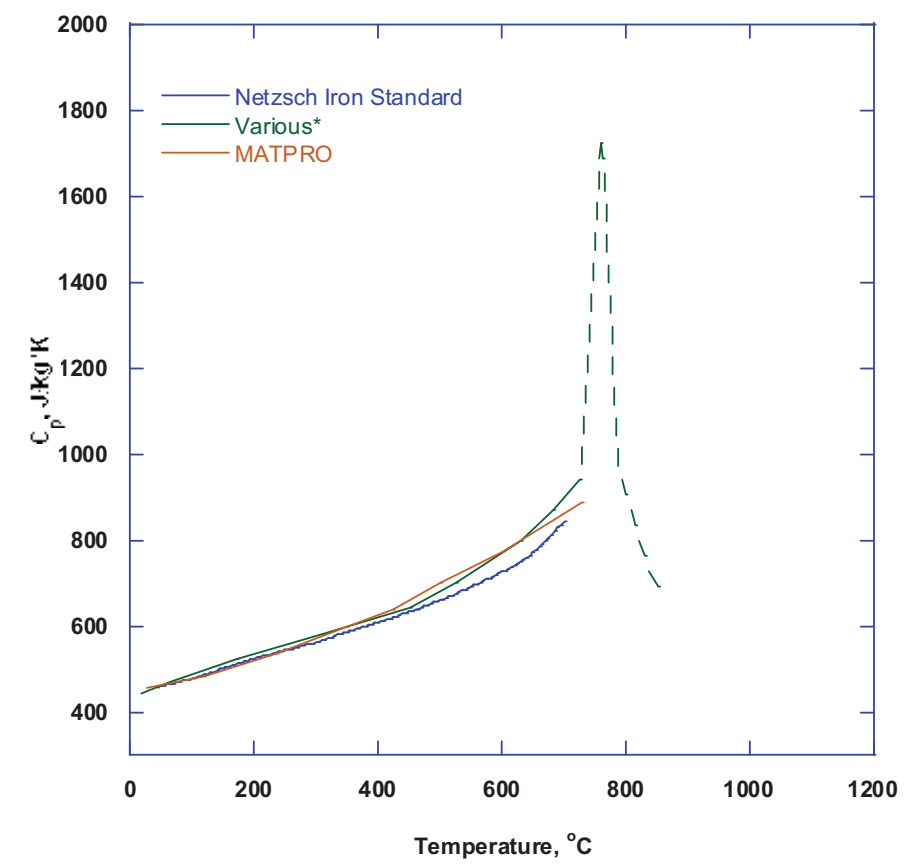

Figure 4-2. Literature values for SA533 specific heat capacity.

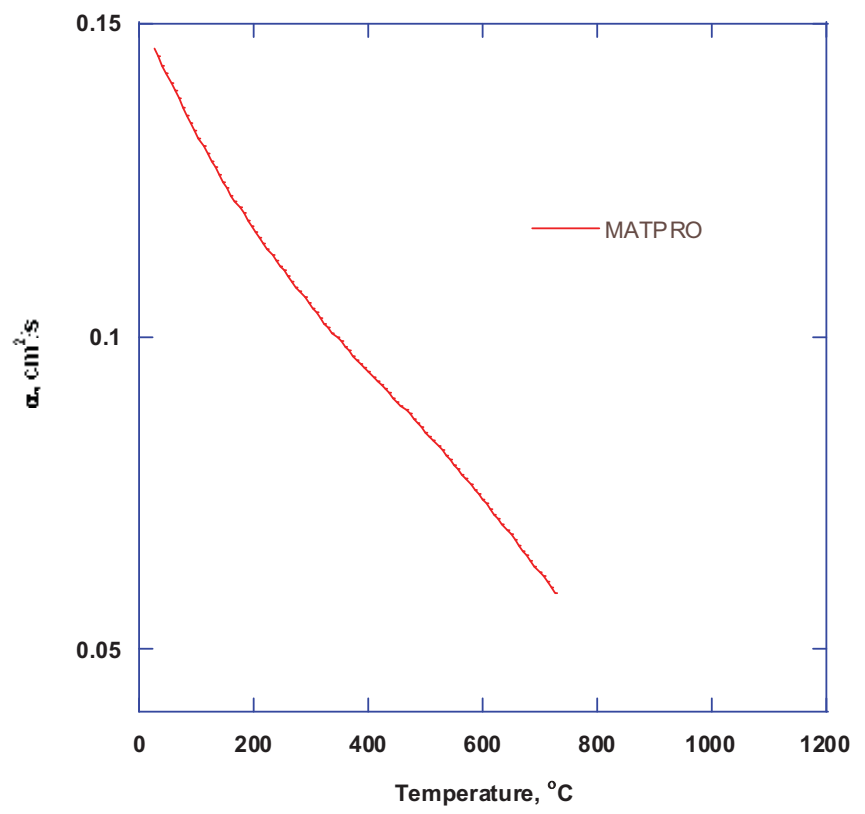

Figure 4-3. Literature values for SA 533 thermal diffusivity.

Figure 4-4 shows thermal conductivity data for SA533 steel. The data show a maximum difference of $12 \%\left(4.4 \mathrm{~W} / \mathrm{m}^{*} \mathrm{~K}\right)$ over the temperature range with data from both sources $\left(310^{\circ} \mathrm{C}\right.$ to $\left.930{ }^{\circ} \mathrm{C}\right)$. 


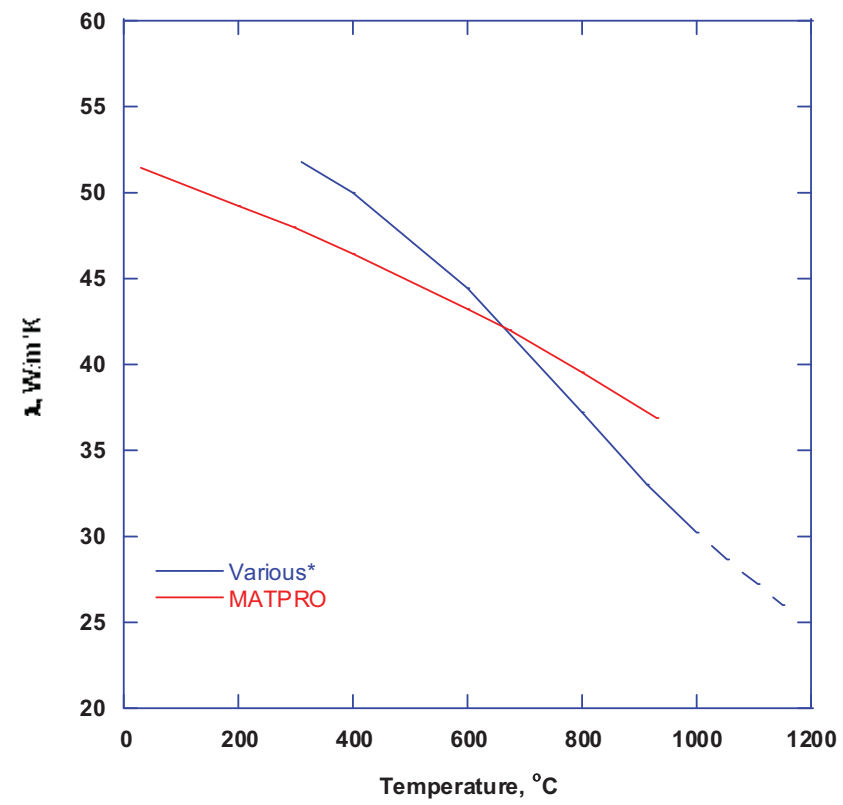

Figure 4-4. Literature values for SA533 thermal conductivity.

\subsection{Stainless Steel}

Figures 4-5 through 4-8 show stainless steel 304 material property data published by Touloukian $^{21}$ (extrapolated for values over $1000^{\circ} \mathrm{C}$ ), as well as data from the MATPRO ${ }^{10}$ library (MATPRO stainless steel density, thermal conductivity, and specific heat data are extrapolated for temperatures above $1000{ }^{\circ} \mathrm{C}$; thermal diffusivity data are based on data collected by Peckner and Berstein $^{22}$, and are extrapolated for temperatures above $730^{\circ} \mathrm{C}$ ). Also shown are specific heat capacity data from Netzsch ${ }^{7}$ and thermal diffusivity data from Anter ${ }^{23}$.

Figure 4-5 shows density data for SS304 stainless steel from Touloukian and MATPRO. At $1000{ }^{\circ} \mathrm{C}$, above which MATPRO data are extrapolated, the difference is $6.3 \%\left(492.5 \mathrm{~kg} / \mathrm{m}^{3}\right)$. At the maximum temperature reported, there is a difference of $7.9 \%\left(619.8 \mathrm{~kg} / \mathrm{m}^{3}\right)$. 


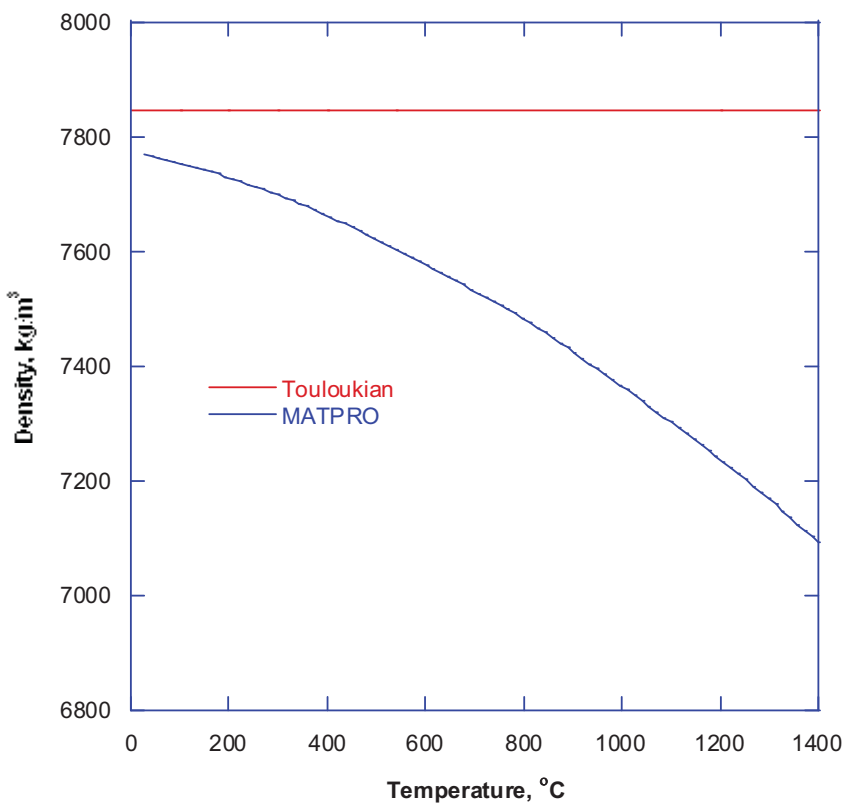

Figure 4-5. Literature values for SS304 density.

Figure 4-6 shows specific heat capacity data for SS304 stainless steel. At the maximum (non-extrapolated) temperature limit, there is a difference of $6.4 \%\left(36.3 \mathrm{~J} / \mathrm{kg}^{*} \mathrm{~K}\right)$ between the Touloukian and MATPRO data. At the minimum reported temperature the difference is $18.7 \%$ (96 $\left.\mathrm{J} / \mathrm{kg}^{*} \mathrm{~K}\right)$. This does not include the Netzsch SS310 data.

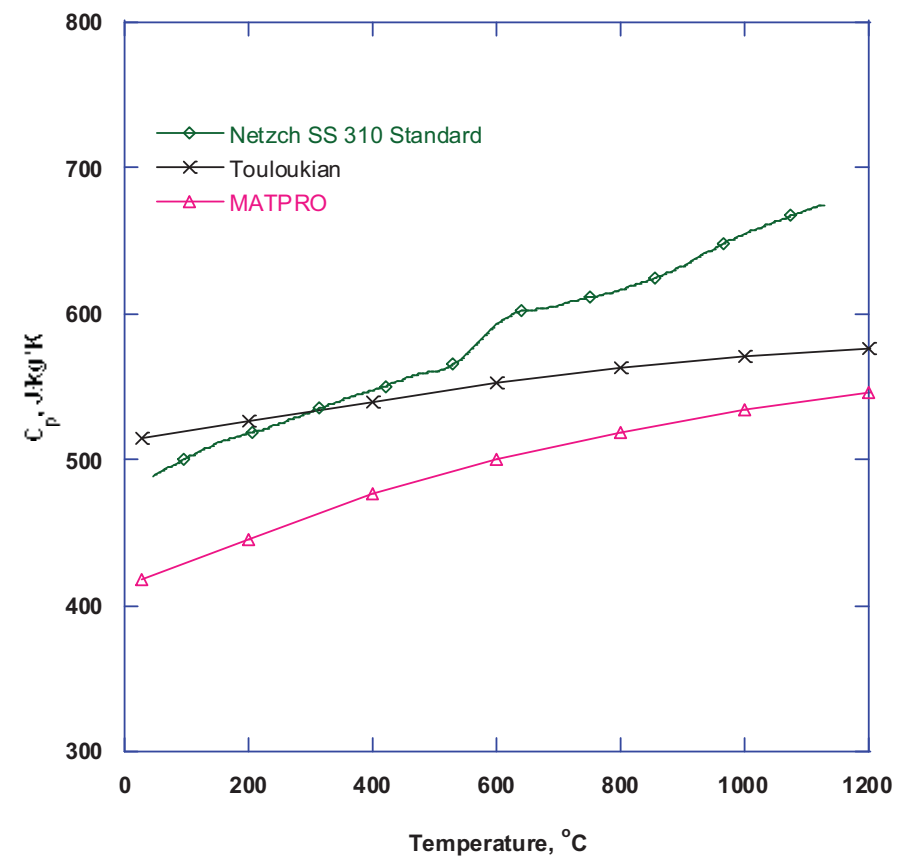

Figure 4-6. Literature values for $\mathrm{SS} 304$ specific heat capacity. 
Figure 4-7 shows thermal diffusivity data for SS304 stainless steel. At the upper temperature limit of the Anter data, there is a difference of $13.3 \%\left(0.008 \mathrm{~cm}^{2} / \mathrm{s}\right)$ between Anter and Touloukian and $27.8 \%\left(0.020 \mathrm{~cm}^{2} / \mathrm{s}\right)$ between Anter and MATPRO. At the upper limit of reported data (near the melting point) there is a difference of $21.8 \%\left(0.021 \mathrm{~cm}^{2} / \mathrm{s}\right)$ between Touloukian and MATPRO.

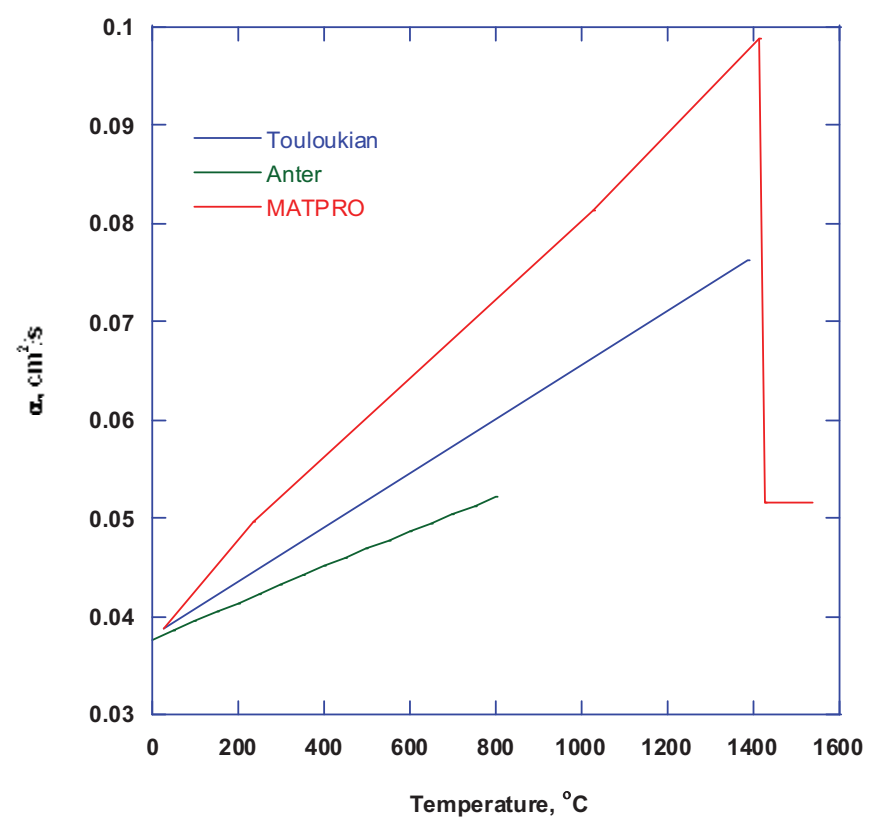

Figure 4-7. Literature values for SS304 thermal diffusivity.

Figure 4-8 shows thermal conductivity data for SS304 stainless steel. The data show a maximum difference of $9.26 \%(2.92 \mathrm{~W} / \mathrm{m} * \mathrm{~K})$ at $1000{ }^{\circ} \mathrm{C}$ (above which MATPRO data are extrapolated). At the maximum reported temperature the difference is $13.1 \%(5.18 \mathrm{~W} / \mathrm{m} * \mathrm{~K})$.

\subsection{Inconel 600}

Figures 4-9 through 4-11 show Inconel 600 material property data published by Touloukian $^{24}$ as well as manufacturers Special Metals, Incorporated (density described as a physical constant) ${ }^{25}$ and Huntington Alloy. ${ }^{26}$ Also shown are specific heat capacity data from Netzsch $^{7}$, and density data from Air Force studies ${ }^{27}$. Extrapolated data are plotted with a dashed line. 


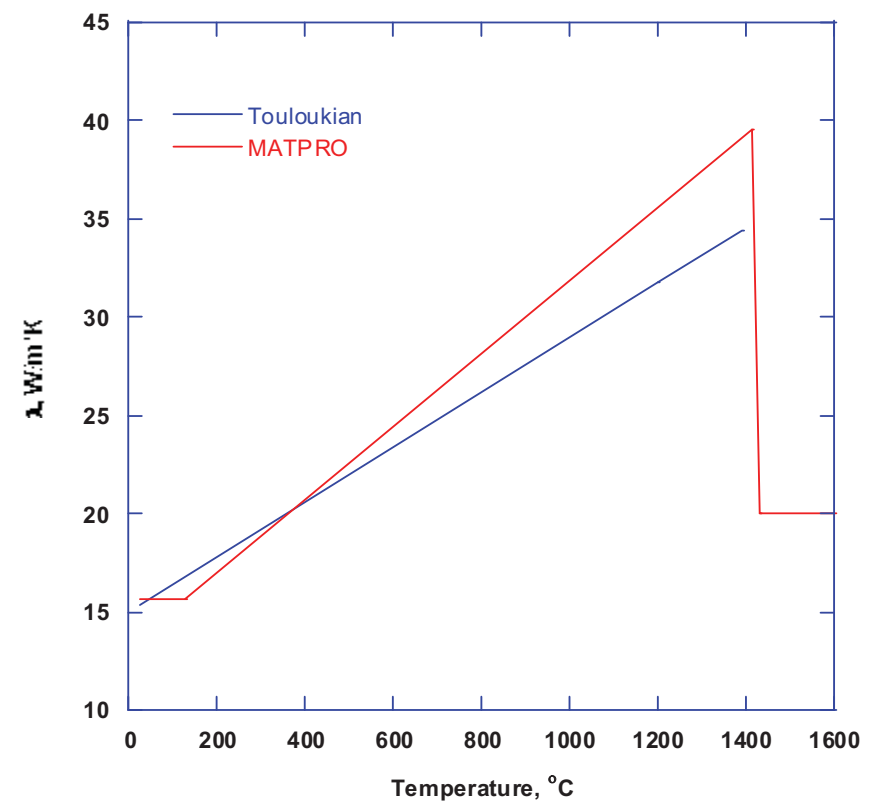

Figure 4-8. Literature values for SS304 thermal conductivity.

Figure 4-9 shows density data for Inconel 600. There is a maximum difference of $3.1 \%$ $\left(270 \mathrm{~kg} / \mathrm{m}^{3}\right)$ between Touloukian and Special Metals data. The difference between Touloukian and Air Force data is an approximately constant value of $4.15 \%\left(357 \mathrm{~kg} / \mathrm{m}^{3}\right)$, the difference in room temperature values reported.

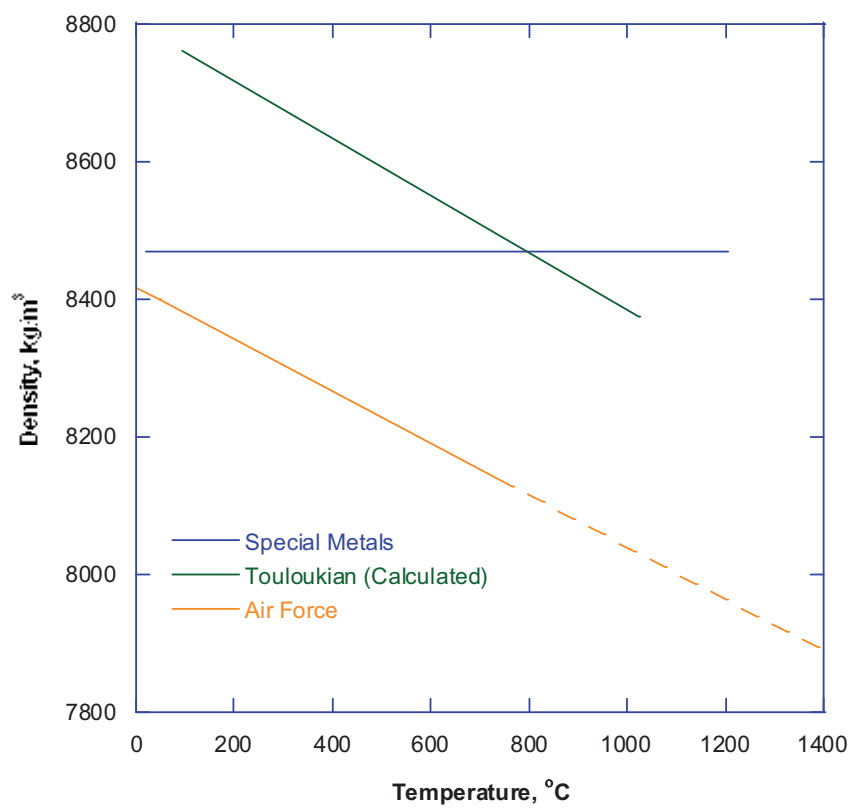

Figure 4-9. Literature values for Inconel 600 density. 
Figure 4-10 shows specific heat capacity data for Inconel 600. There is a maximum difference of $8.3 \%\left(55.4 \mathrm{~J} / \mathrm{kg}^{*} \mathrm{~K}\right)$ between the Touloukian and Netzsch data.

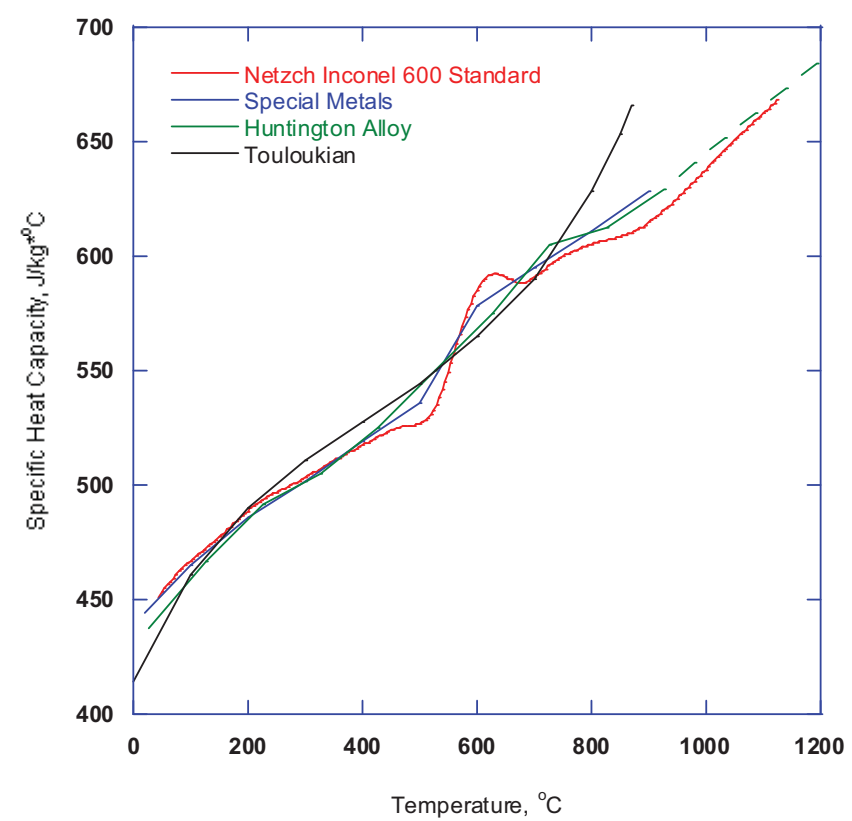

Figure 4-10. Literature values for Inconel 600 specific heat capacity.

Figure 4-11 shows thermal conductivity data for Inconel 600. The data show a maximum difference of $19.3 \%\left(2.8 \mathrm{~W} / \mathrm{m}^{*} \mathrm{~K}\right)$. Data from Special Metals and Huntington Alloy are very consistent. 


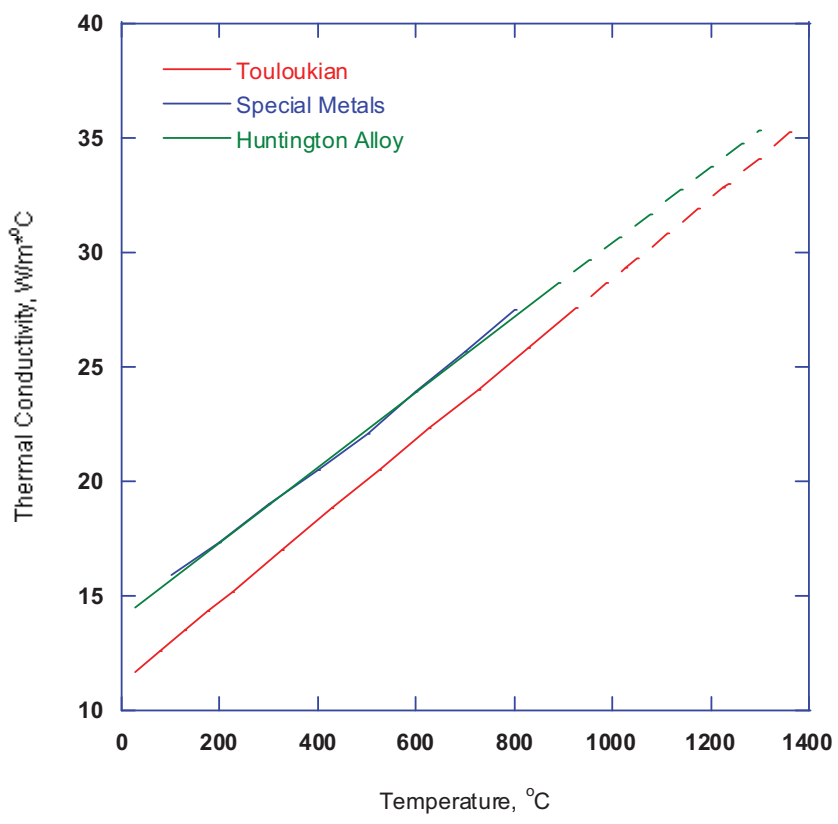

Figure 4-11. Literature values for Inconel 600 thermal conductivity. 


\section{Results}

In the following subsections, results of testing carried out by INL are compared to data found in reference sources. All tests were carried out with multiple test samples (average values are reported). Tests were carried out using recommendations from equipment manufacturers regarding dimensioning of samples, surface treatments, etc.

Reported data include thermal conductivity calculation results and all property data required to make the calculations per the method outlined in Section 3 (thermal expansion, density, specific heat, and thermal diffusivity).

\subsection{SA533-B1 Low Alloy Steel}

Figure 5-1 shows linear thermal expansion data for SA 533-B1 low alloy carbon steel collected at the HTTL (measured using a pushrod dilatometer). Also shown are data from MATPRO. The INL data are lower than the MATPRO data, but more notable is that the MATPRO data do not extend to temperatures above $730{ }^{\circ} \mathrm{C}$ (where a solid state phase transformation occurs). The transition from body centered cubic to face centered cubic is clearly visible as a drop in sample length during the reordering process between temperatures of approximately $740{ }^{\circ} \mathrm{C}$ and $840{ }^{\circ} \mathrm{C}$.

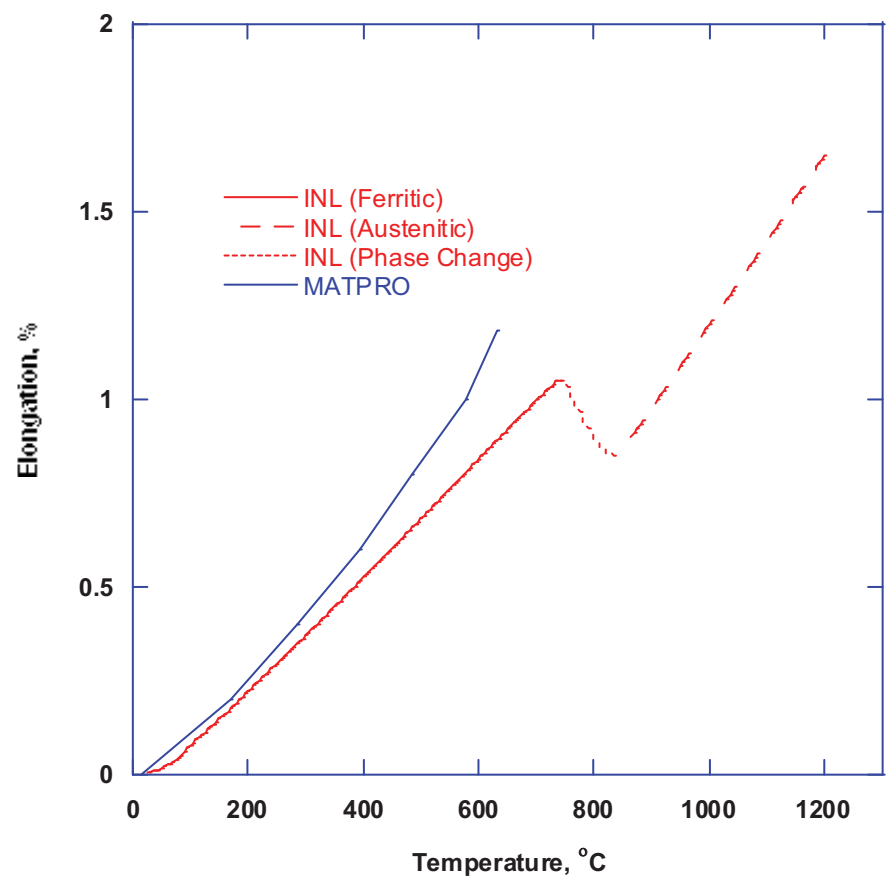

Figure 5-1. Comparison of INL SA533 thermal expansion data with literature sources. 
Figure 5-2 shows density data for SA 533-B1 low alloy carbon steel derived from the measured thermal expansion using Equation (1). Also shown are data from MATPRO and Neimark. As with thermal expansion, the INL data are lower than the MATPRO data, which does not extend to temperatures above $730{ }^{\circ} \mathrm{C}$, by a maximum of $1.4 \%\left(106.3 \mathrm{~kg} / \mathrm{m}^{3}\right)$. INL data are in close agreement with Neimark data, which does not extend beyond $427{ }^{\circ} \mathrm{C}$.

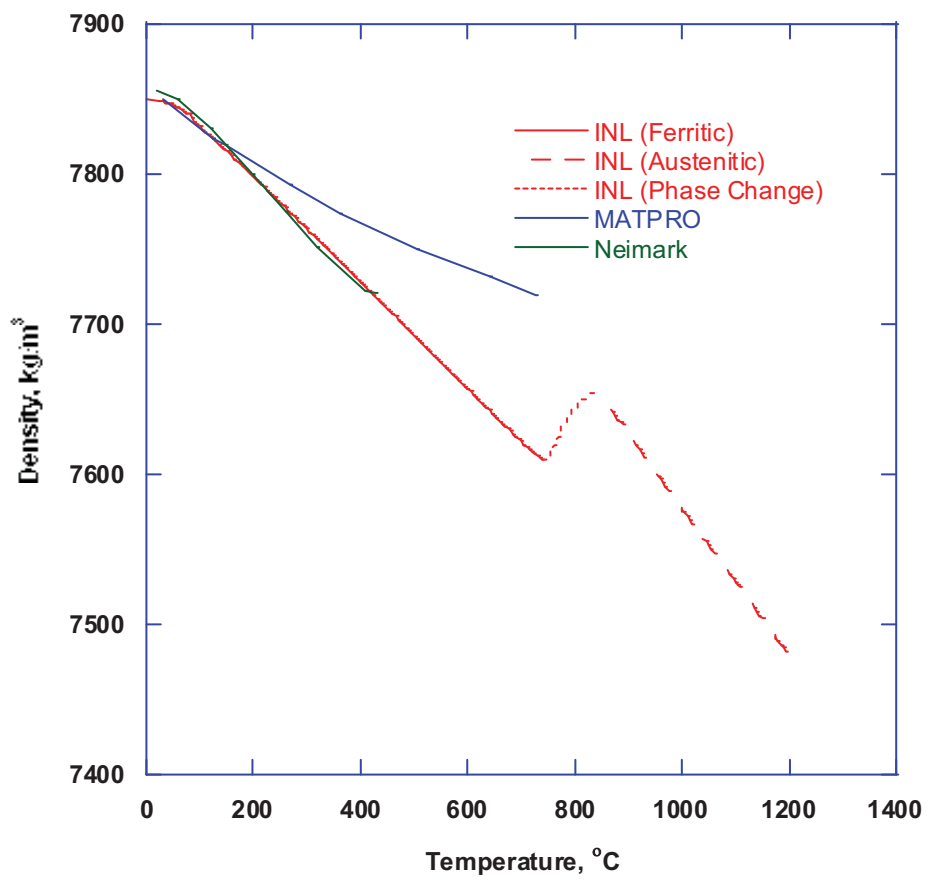

Figure 5-2. Comparison of INL SA533 density data with literature sources.

Figure 5-3 shows average specific heat capacity data for SA 533-B1 low alloy carbon steel collected at the HTTL (measured using a differential scanning calorimeter). Also shown are data from MATPRO and References 13 through 18. Also shown, for comparison, are data from a Netzsch iron standard. The large spike apparent in the INL data corresponds to the solid state phase change (also observed in the thermal expansion data). The curve represents energy absorbed by the sample as it is heated (specific heat capacity is the amount of energy required to cause a temperature change); during the phase change much of this energy is used in the restructuring of the material. This spike is, therefore, not a good indicator of the true specific heat of the sample in the temperature range of the phase change. To account for this, Netzsch (the DSC manufacturer) recommends interpolating between the onset and end temperatures of the phase change, using either a linear or tangential interpolation, to calculate the specific heat. This is accomplished using software provided with the DSC. The temperature limits are not easy to define from the DSC data, however. The onset of a phase change during a heating cycle is useful, but the end temperature may be difficult to estimate. To get a good estimate of the temperature range for the phase change, values were determined using thermal expansion data from the dilatometer measurements. Using a linear interpolation, the specific heat during phase change was estimated, as was the latent heat of phase change (the area under the spike). The specific heat data 
curve, with estimated latent heat and bounding temperature values is shown in Figure 5-4. Data collected at temperatures below the phase change onset differ from MATPRO values by a maximum of $16.1 \%\left(170.6 \mathrm{~J} / \mathrm{kg}^{*} \mathrm{~K}\right)$ and from References 13 through 18 data by $10.8 \%(114.4$ $\mathrm{J} / \mathrm{kg} * \mathrm{~K})$.

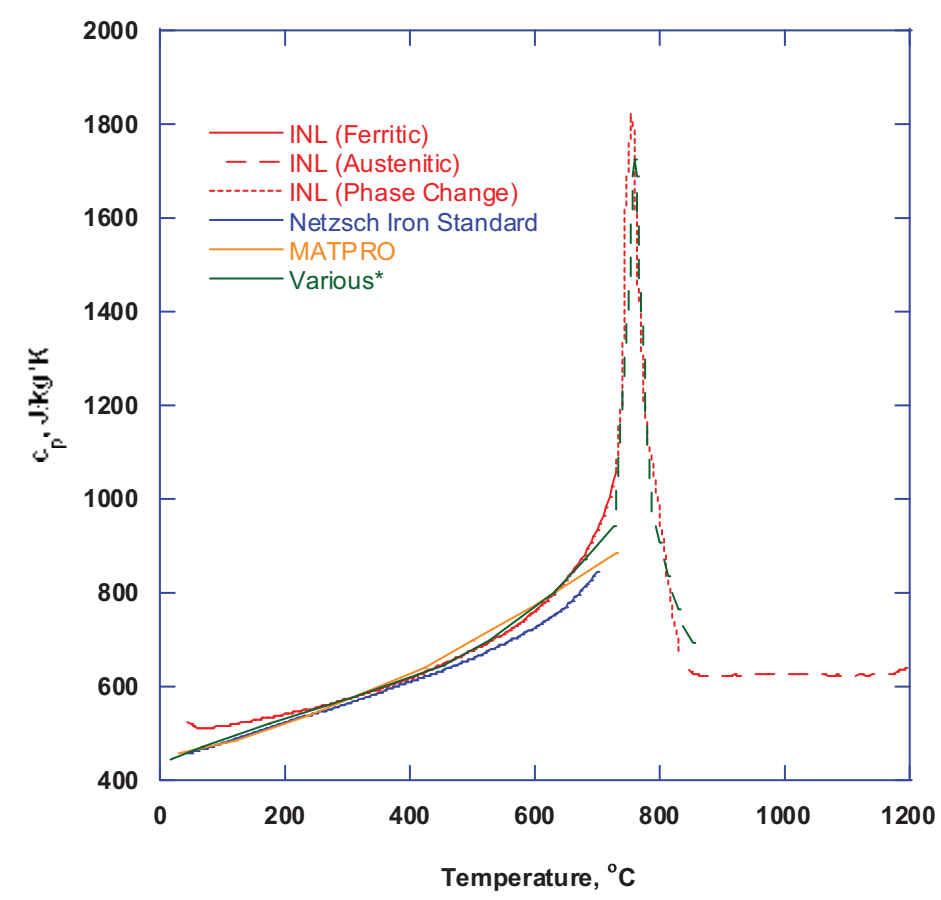

Figure 5-3. Comparison of INL SA533 specific heat capacity data with literature sources.

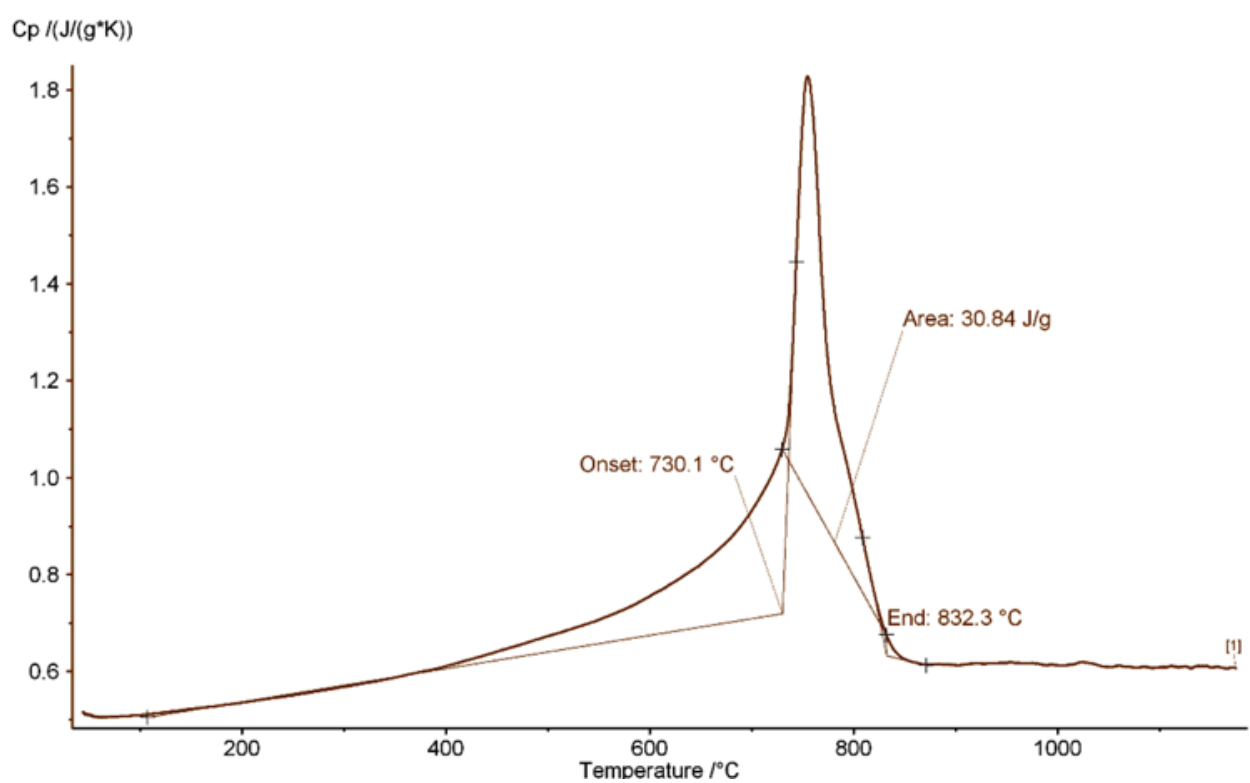

Figure 5-4. SA 533 specific heat capacity curve with estimated phase change temperatures and enthalpy change as calculated using Netzsch software. 
Figure 5-5 shows data collected for SA 533 thermal diffusivity. Also shown are data from the MATPRO library and from previous INL tests. Again, there is a significant change in behavior apparent in the temperature range of phase change. Data from INL tests are in close agreement, though there is an offset from the MATPRO data, with a maximum difference of $31.7 \%(0.019$ $\left.\mathrm{cm}^{2} / \mathrm{s}\right)$.

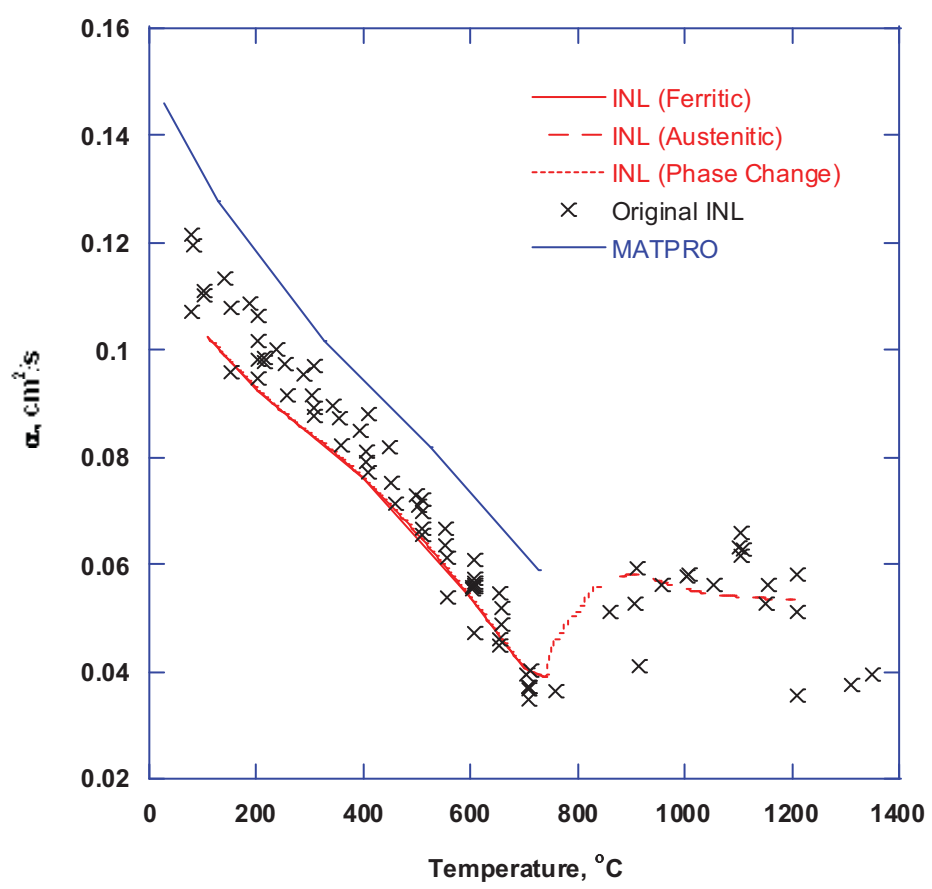

Figure 5-5. Comparison of INL SA533 thermal diffusivity data with literature sources.

Thermal conductivity data for SA 533 is shown in Figure 5-6. INL data were calculated using Equation (2). Also shown are data from MATPRO and References [19] and [20]. It should be noted that INL values for thermal conductivity in the temperature range associated with phase change should be considered approximate. There is a clear change in behavior between the ferritic and austenitic phases, as the slope of the thermal conductivity curves changes. The maximum difference between INL and MATPRO data occurs just below the onset of phase change (MATPRO data is extrapolated above this temperature). This difference is $11.9 \%(4.4 \mathrm{~W} / \mathrm{m} * \mathrm{~K})$. Because the INL data is piece-wise defined, a fifth order polynomial fit is recommended. Coefficients for the equation are listed in the figure.

\subsection{Stainless Steel}

Figure 5-7 shows linear thermal expansion data for 304 stainless steel collected at the HTTL (measured using a pushrod dilatometer). Also shown are data from MATPRO and 


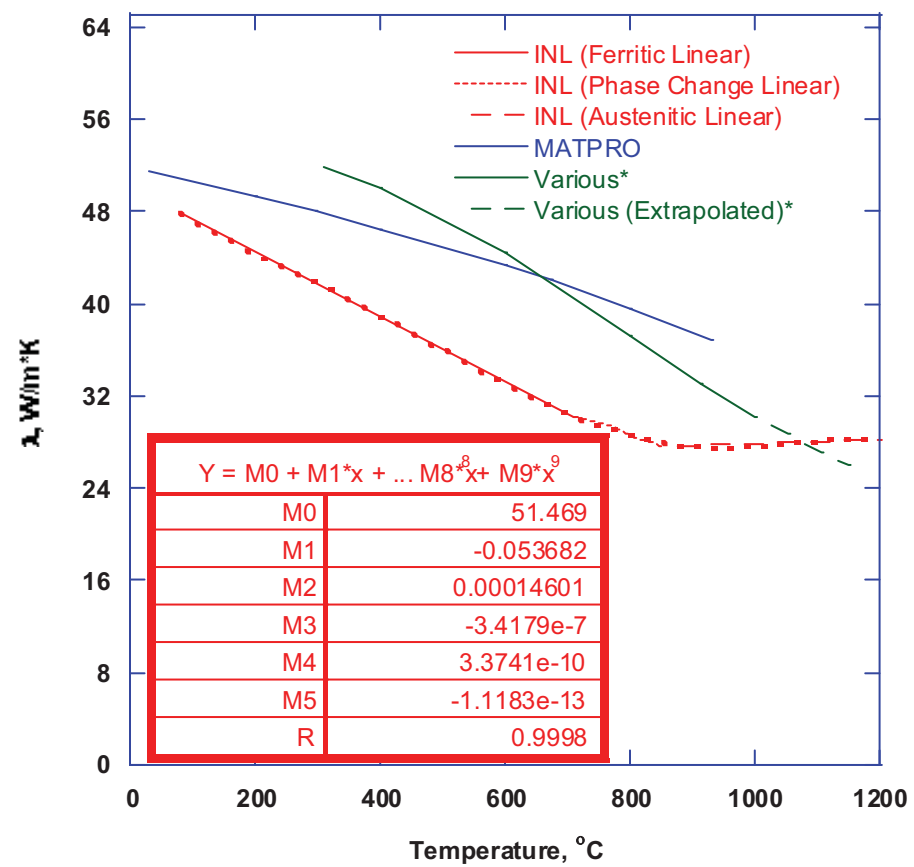

Figure 5-6. Comparison of INL SA533 thermal conductivity data with literature sources.

Touloukian. INL data are in close agreement with both Touloukian and MATPRO data, both of which are extrapolated for high temperatures (illustrated with dashed lines).

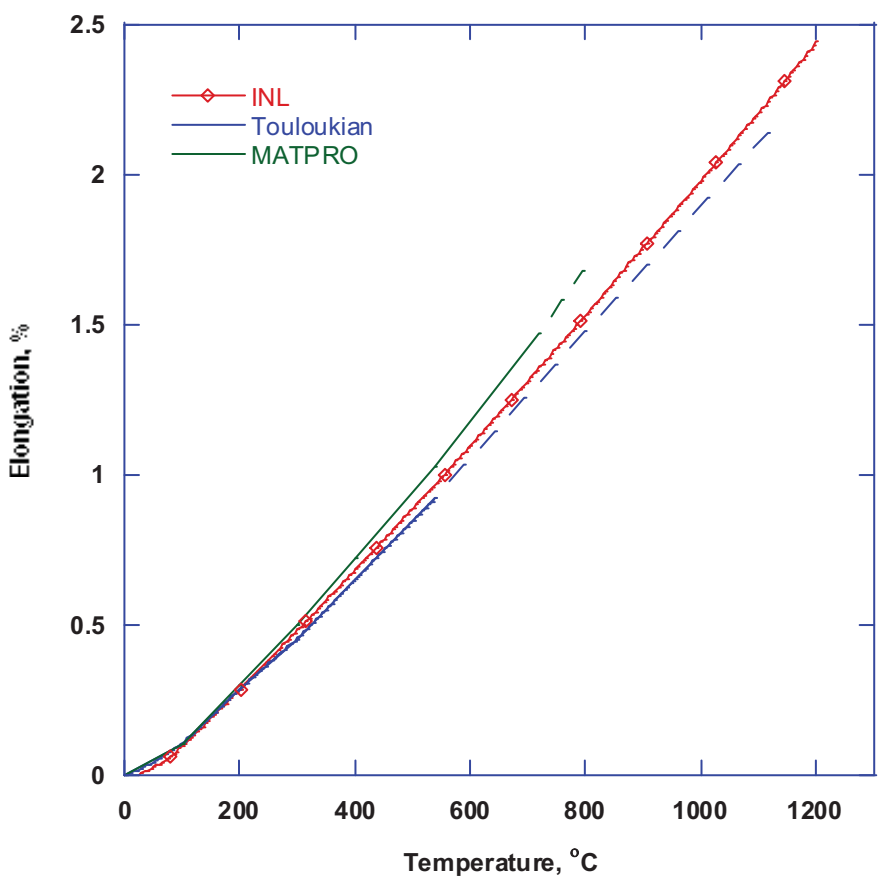

Figure 5-7. Comparison of INL SS 304 thermal expansion data with literature sources. 
Figure 5-8 shows density data for 304 stainless steel derived from the measured thermal expansion data using Equation (1). Also shown are data from MATPRO and Touloukian. INL data closely match MATPRO data up to approximately $1000{ }^{\circ} \mathrm{C}$. MATPRO data are extrapolated beyond this temperature. The difference between MATPRO and INL data has a maximum value of $1.02 \%\left(74.3 \mathrm{~kg} / \mathrm{m}^{3}\right)$, while INL varies from Touloukian by a maximum of $7.3 \%\left(535.3 \mathrm{~kg} / \mathrm{m}^{3}\right)$.

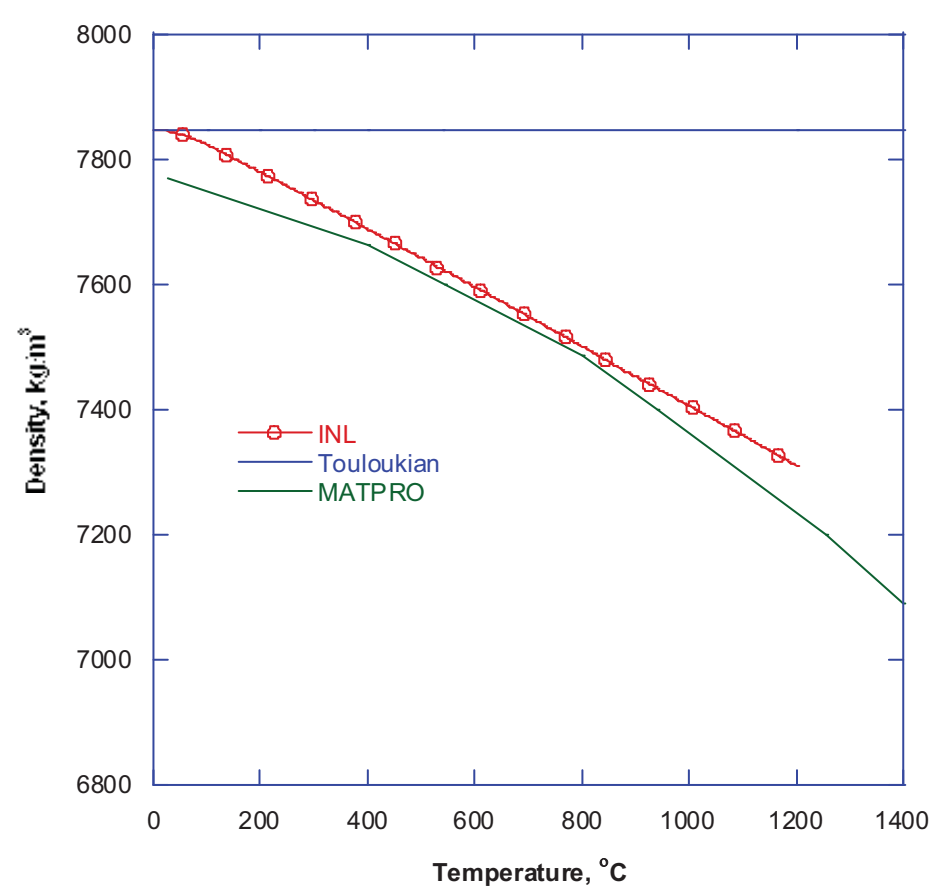

Figure 5-8. Comparison of INL SS 304 density data with literature sources.

Figure 5-9 shows average specific heat capacity data for 304 and 304L stainless steel collected at the HTTL (measured using a differential scanning calorimeter). Also shown are data from MATPRO and Touloukian. Also shown for comparison are Netzsch data for 310 stainless steel. The data recorded in the INL closely match the Netzsch standard data. Furthermore, the data are very close to the data from Touloukian for temperatures up to approximately $600{ }^{\circ} \mathrm{C}$, at which point the INL and Netzsch data show a slight "bump." This bump in data at $600{ }^{\circ} \mathrm{C}$ is indicative of carbide formation. The maximum difference between INL and Touloukian data is $10.4 \%$ (59.8 $\left.\mathrm{J} / \mathrm{kg}{ }^{*} \mathrm{~K}\right)$ at $1200{ }^{\circ} \mathrm{C}$, the upper limit of INL data. The difference between INL and MATPRO data, approximately constant over the temperature range of INL data, is $18 \%(85 \mathrm{~J} / \mathrm{kg} * \mathrm{~K})$.

Figure 5-10 shows INL data collected for 304 stainless steel thermal diffusivity. Also shown are data previously collected at INL, as well as data from Touloukian, Anter, and the MATPRO library. INL data (both from recent and earlier tests) are consistent with the Anter and Touloukian data (Touloukian data were extrapolated above $1000^{\circ} \mathrm{C}$ ) differing from Anter data by a maximum of $2.7 \%\left(0.0015 \mathrm{~cm}^{2} / \mathrm{s}\right)$ and from Touloukian data by $16.9 \%\left(0.012 \mathrm{~cm}^{2} / \mathrm{s}\right)$. The INL data also match the MATPRO data for lower temperatures but are much lower at high 


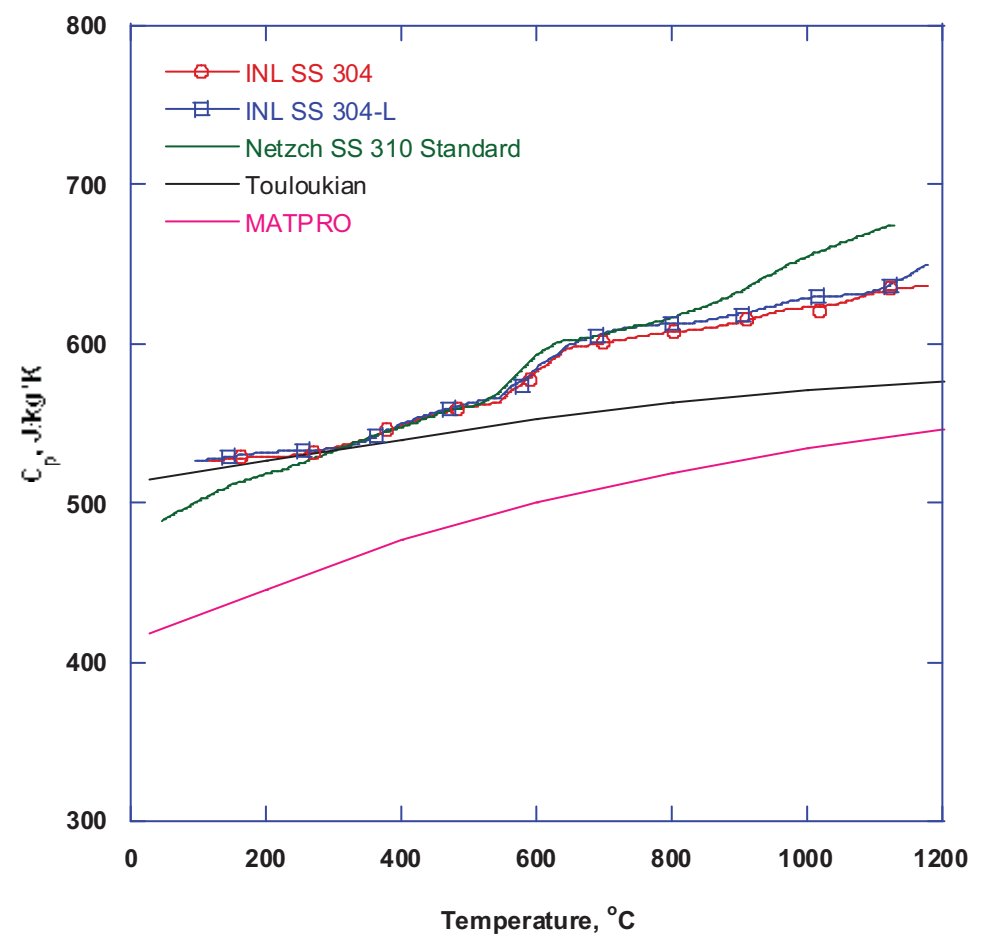

Figure 5-9. Comparison of INL SS304 specific heat capacity data with literature sources.

temperatures (MATPRO data were extrapolated above $730{ }^{\circ} \mathrm{C}$ ), with a maximum difference of $33.6 \%\left(0.03 \mathrm{~cm}^{2} / \mathrm{s}\right)$.

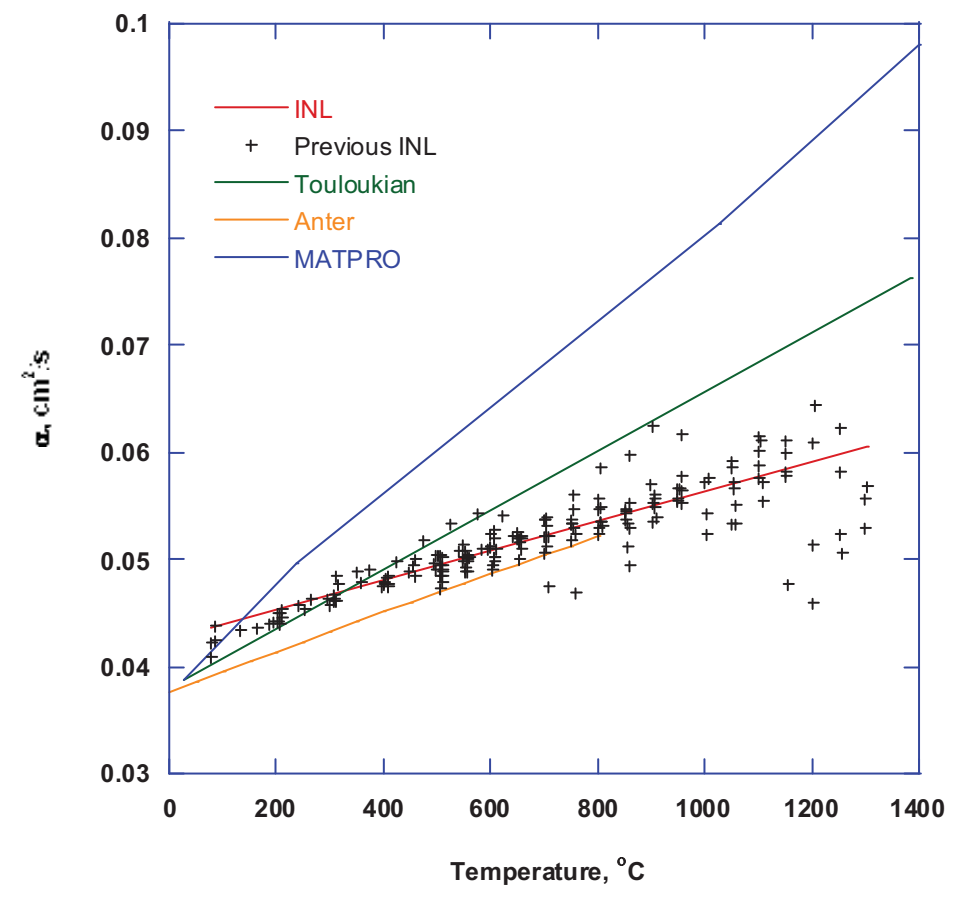

Figure 5-10. Comparison of INL SS304 thermal diffusivity data with literature sources. 
Figure 5-11 shows the calculated (from Equation 1) thermal conductivity of 304 stainless steel. Also shown are data from Touloukian and MATPRO. Despite some differences in the measured property data used to calculate thermal conductivity, INL data are in close agreement with both literature sources (both of which were extrapolated for temperatures above $1000{ }^{\circ} \mathrm{C}$ ). At $1000{ }^{\circ} \mathrm{C}$, INL data differs from MATPRO data by $13.43 \%\left(4.3 \mathrm{~W} / \mathrm{m}^{*} \mathrm{~K}\right)$ and from Touloukian data by $4.7 \%\left(1.4 \mathrm{~W} / \mathrm{m}^{*} \mathrm{~K}\right)$. At $1200{ }^{\circ} \mathrm{C}$, the maximum temperature represented in INL data, INL data differs from MATPRO data by $13.40 \%\left(4.8 \mathrm{~W} / \mathrm{m}^{*} \mathrm{~K}\right)$ and from Touloukian data by $2.9 \%(0.9$ $\mathrm{W} / \mathrm{m} * \mathrm{~K})$.

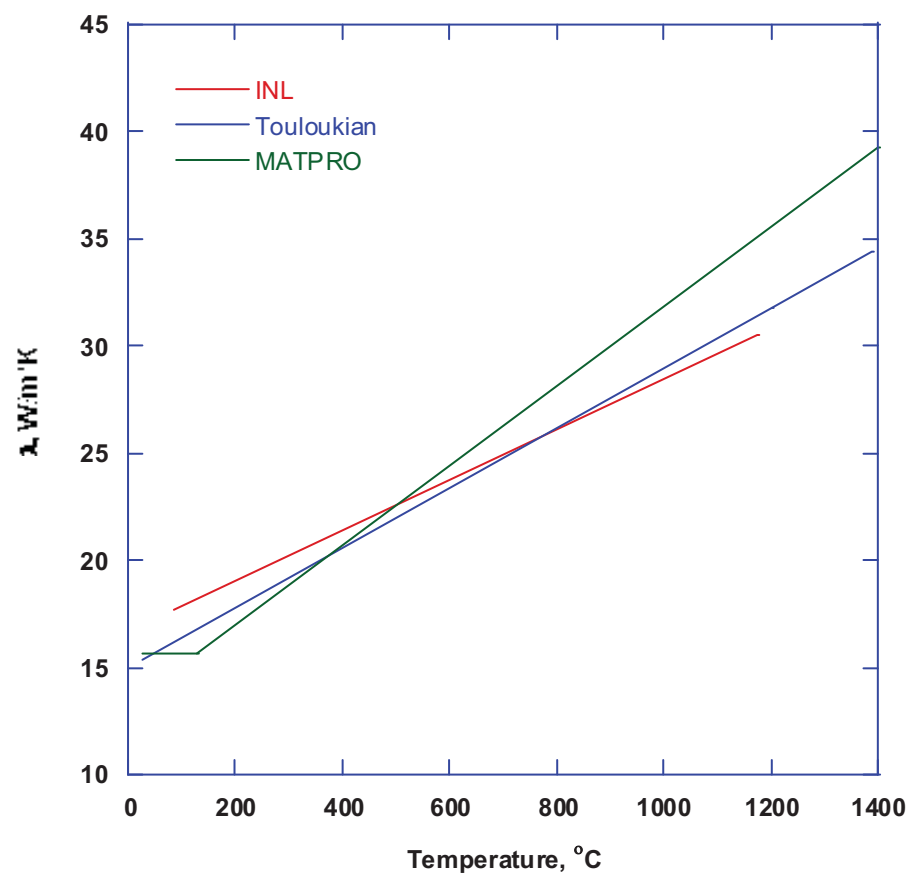

Figure 5-11. Comparison of INL SS304 thermal conductivity data with literature sources.

\subsection{Inconel 600}

Figure 5-12 shows linear thermal expansion data for Inconel 600 collected at the HTTL (measured using a pushrod dilatometer). Also shown are data from Touloukian. INL data are in close agreement with Touloukian data for temperatures up to approximately $1050{ }^{\circ} \mathrm{C}$, at which point the Touloukian data shows a slight increase relative to INL data.

Figure 5-13 shows INL density data for Inconel 600. Also plotted are data from Touloukian, manufacturer Special Metals Inc. (described in literature as a physical constant) and Air Force studies. Data from Touloukian were calculated from thermal expansion data in the same 


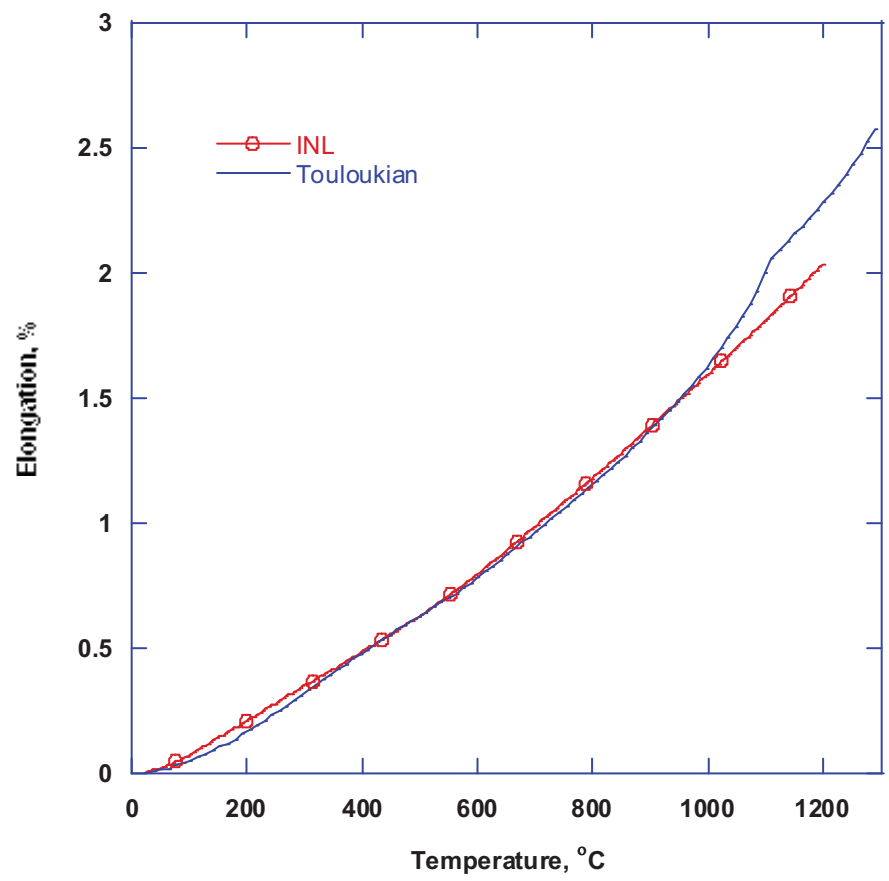

Figure 5-12. Comparison of INL Inconel 600 thermal expansion data with literature sources.

manner as INL data. INL data closely match Touloukian values differing by a maximum of $0.5 \%$ $\left(43.5 \mathrm{~kg} / \mathrm{m}^{3}\right)$. INL data also matches the trend shown in Air Force data, though the Air Force data are significantly lower, differing by a nearly constant $3.9 \%\left(330 \mathrm{~kg} / \mathrm{m}^{3}\right)$.

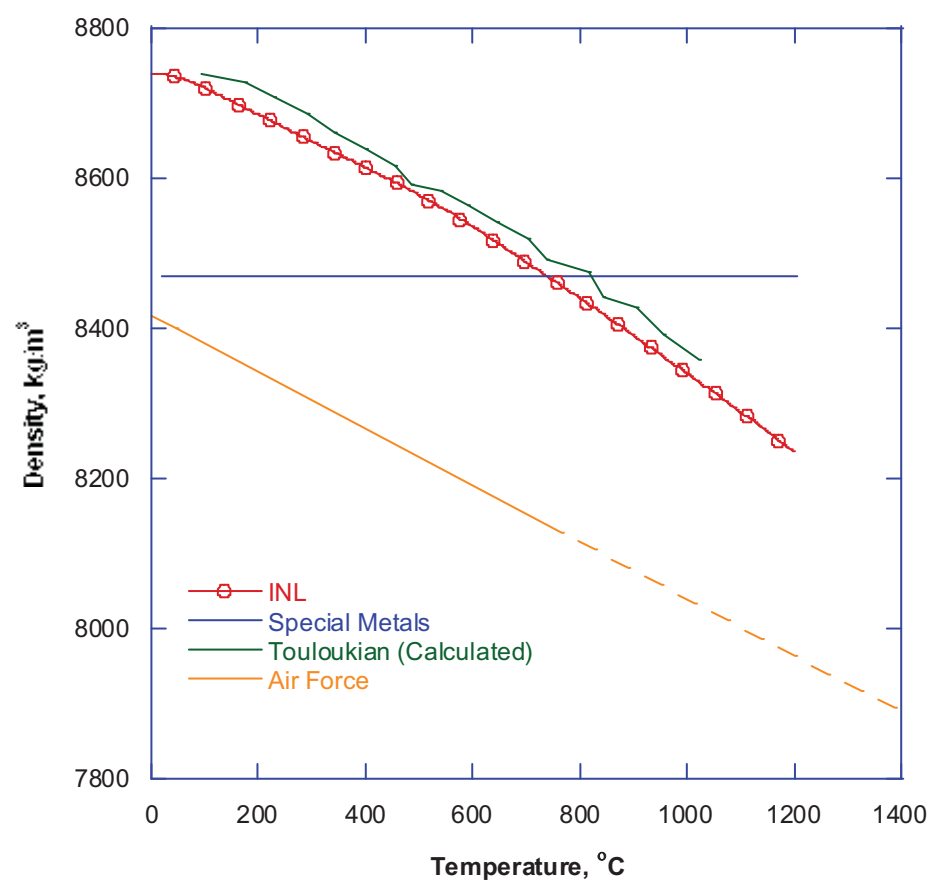

Figure 5-13. Comparison of INL Inconel 600 density data with literature values. 
Figure 5-14 shows specific heat capacity data for Inconel 600 collected at the HTTL (measured using a differential scanning calorimeter). Also shown are data from Touloukian, Netzsch, and manufacturers Special Metals and Huntington Alloy. The data recorded in the INL closely match the literature data. INL data differs from Netzsch data by a maximum of $10.2 \%$ $\left(58.7 \mathrm{~J} / \mathrm{kg}^{*} \mathrm{~K}\right)$ and from Touloukian data by a maximum of $8.3 \%\left(55.1 \mathrm{~J} / \mathrm{kg}^{*} \mathrm{~K}\right)$. Data from INL Netzsch and Special Metals show a "bump" in specific heat between $500{ }^{\circ} \mathrm{C}$ and $700{ }^{\circ} \mathrm{C}$ corresponding to formation of $\mathrm{NiCr}_{3}$ clusters. ${ }^{28}$

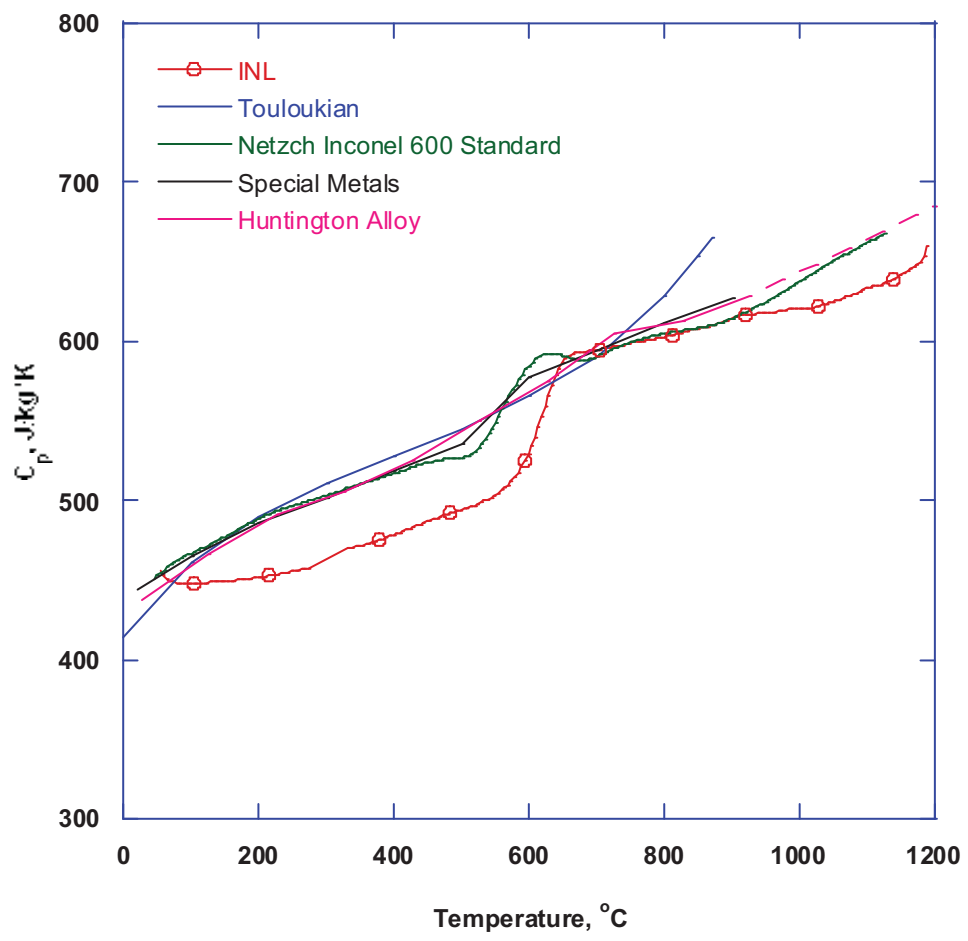

Figure 5-14. Comparison of INL Inconel 600 specific heat capacity data with literature sources.

Figure 5-15 shows INL thermal diffusivity data for Inconel 600. No reference data were available for comparison. The data show a "bump" in the same temperature range as that seen for specific heat, this may also be an effect of $\mathrm{NiCr}_{3}$ cluster formation.

Figure 5-16 shows thermal conductivity data calculated for Inconel 600. Also shown are data from Touloukian and manufacturers Special Metals and Huntington alloy. INL data are consistent with reference sources, differing from Touloukian data by a average of $1.4 \%$ $\left(8.5 \mathrm{~W} / \mathrm{m}^{*} \mathrm{~K}\right)$. 


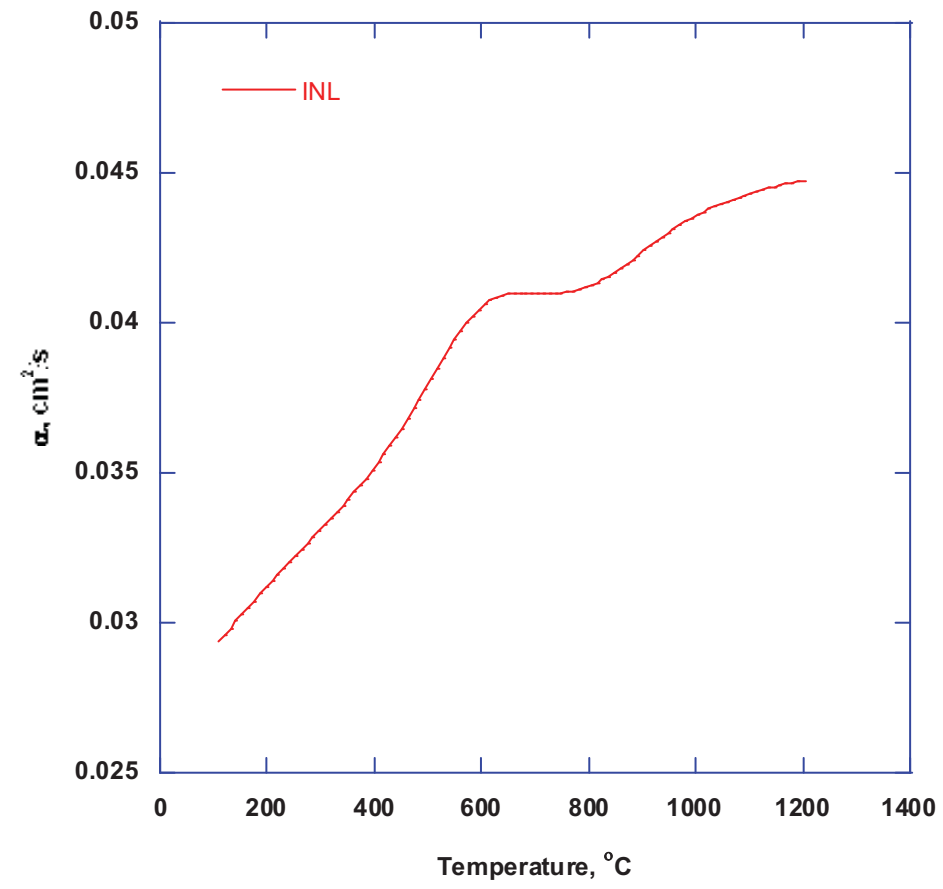

Figure 5-15. INL Inconel 600 thermal diffusivity data.

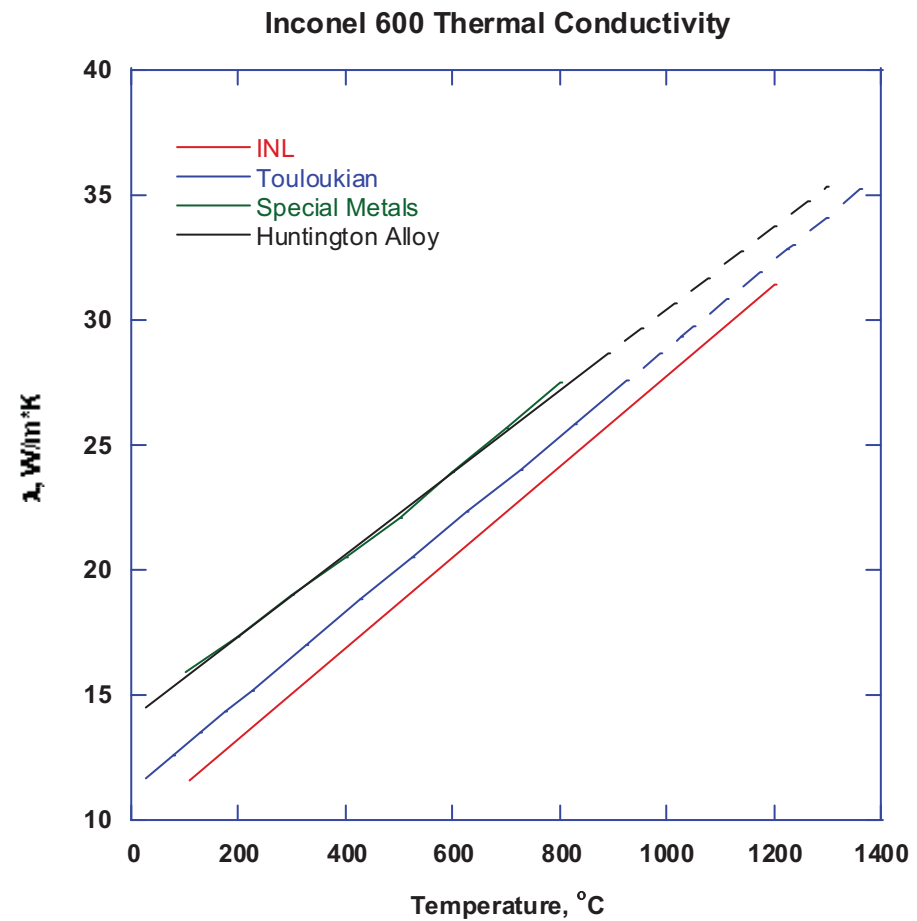

Figure 5-16. Comparison of INL Inconel 600 thermal conductivity data with literature sources. 
INL/EXT-09-16121 


\section{Summary}

Thermal property data for SA533-B1 low carbon steel, 304 stainless steel, and Inconel 600 were collected at Idaho National Laboratory's High Temperature Test Laboratory. Data for thermal expansion, specific heat capacity, and thermal diffusivity up to $1200{ }^{\circ} \mathrm{C}$ were collected. These data were used to calculate density and thermal conductivity, which were then compared to reference data. SA533 exhibited a solid state phase change between temperatures of approximately $740{ }^{\circ} \mathrm{C}$ and $840{ }^{\circ} \mathrm{C}$. Although this behavior had significant effect on INL data, few examples of literature data indicate the presence of this behavior. It is also interesting to note that although much of the data collected for 304 stainless steel and Inconel 600 differed from literature sources, the resulting thermal conductivity values were very close to accepted values. 
INL/EXT-09-16121

6-2 


\section{References}

1. J. L. Rempe and D. L. Knudson, "High Temperature Thermal Properties for Metals used in LWR Vessels," Journal of Nuclear Materials, 372, January 2008, pp 350-357.

2. J. L. Rempe, D. L. Knudson, K. G. Condie, "Thermal Properties for Candidate SCWR Materials," INL/EXT-05-01030, Idaho National Laboratory, December 2005.

3. J. E. Daw, et al., "Thermal Expansion Coefficient of Steels used in LWR Vessels,"Journal of Nuclear Materials, Volume 376, Issue 2, 31 May 2008, Pages 211-215.

4. J. E. Daw, et al., "Viability of Pushrod Dilatometry Techniques for High Temperature In-Pile Measurements," INL/EXT-07-13120, Idaho National Laboratory, March 2008.

5. J. E. Daw, "Measurement of Specific Heat Capacity Using Differential Scanning Calorimeter," INL/EXT-08-15056, Idaho National Laboratory, November 2008.

6. J. E. Daw, "Measurement of Thermal Diffusivity Using a Laser Flash Thermal Property Analyzer," INL/EXT-08-14862, Idaho National Laboratory, November 2008.

7. NETZSCH Proteus Thermal Analysis, Version 4.8.5, Selb, Germany: NETZSCH, 2008.

8. Parker, W.J., R.J. Jenkins, C. P. Butler, and G. L. Abbot, "Flash Method of Determining Thermal Diffusivity, Heat Capacity, and Thermal Conductivity," Journal of Applied Physics, 32 (9): 16791684, 1969.

9. Clark, III, L. M. and R. E. Taylor, "Radiation Loss in the Flash Method for Measurement of Thermal Diffusivity," Journal of Applied Physics, 34(7):1909-1913, 1975.

10. Idaho National Engineering and Environmental Laboratory, SCDAP/RELAP5-3D॰ Code Manuals - Volume 4 - MATPRO-A Library of Materials Properties for Light-Water-Reactor Accident Analysis, INEEL/EXT-02-00589, Idaho National Engineering and Environmental Laboratory, May 2002 .

11. J. C. Spanner et al., Nuclear Systems Material Handbook, TID-26666, April 1976.

12. B. E. Neimark and V. E. Lynsternik, "Effect of Chilling on the Thermal Diffusivity of Carbon Steels," Teploenergetika, 7, 1960, pp. 16-18.

13. J.H Awbery, A. R. Challoner, P. R. Pallister, R. W. Powell, "The Physical Properties of a Series of Steels - Part II," Journal of the Iron Steel Institute, 154, 2, London, 1946, pp. 83-111.

14. P. R. Pallister, "Specific Heat and Resistivity of Mild Steel," Journal of the Iron Steel Institute, 185, 4, London, 1957, pp. 474-482.

15. British Iron and Steel Research Association, Physical Constants of Some Commercial Steels at Elevated Temperatures, London: Butterworth's Scientific Publication, Ltd., 1953, p. 38.

16. E. Griffiths, R. W. Powell, M. J. Hickman, The Physical Properties of a Series of Steels - I, Special Report No. 24, London: Iron Steel Institute, 1939, pp. 215-251. 
17. E. G. Shuidkovskii, "Measurement of the Thermal Conductivity of Metals by the Method of Angström,” J. Tech. Phys., 8, USSR, 1938, pp. 935-947.

18. G. V. Smith, Evaluations of the Elevated Temperature Tensile and Creep Rupture Properties of C$\mathrm{Mo}, \mathrm{Mn}-\mathrm{Mo}$, and Mn-Mo-Ni Steels, Metal Properties Council, American Society for Testing and Materials, ASTM Data Series Publication DS47, 1971

19. K. Honda and T. Simidu, "On the Thermal and Electrical Conductivities of Carbon Steels at High Temperature," Science Reports of Tohoku University, 6, 1917-18, pp. 219-234.

20. D. L. Timrot, "Determination of Thermal Conductivity and Heat Capacity of Steels," Zhurnal Tekhinicheskoi Fisiki, 5, 1935, pp. 1011-1036

21. Y. S. Touloukian, et al., Thermophysical Properties of Matter, IFI/Plenum Publishing, New York, New York, 1973.

22. D. Peckner and I.M Berstein (eds.), Handbook of Stainless Steel, New York: McGraw-Hill BookCompany, 1977, pp. 19-3 - 19-26.

23. Anter Laboratories, Inc., Declarations of Reference Material Conformity, Pittsburgh, PA.

24. Y. S. Touloukian, et al., Thermophysical Properties of Matter, IFI/Plenum Publishing, New York, New York, 1970.

25. Special Metals Inc., Inconel Alloy 600, http://www.specialmetals.com/products/inconelalloy600.php, Publication Number SMC-027, published Sept. 20, 2008, Web page visited Feb. 18, 2009.

26. Huntington Alloy, Inconel Alloy 600, Technical Bulletin of the International Nickel Company, Inc., Huntington Alloy Products Division, Seventh Edition, Huntington, WV, 1978

27. Aerospace Structural Metals Handbook, Air Force Materials Laboratory, 1990 Edition, Revised December 1990

28. NETZSCH., Nickel Based Super Alloy (Inconel Alloy 600), 103-2006-LFA457-Metals-AerospaceIncone1600[1].pdf, Publication Number AS-103-2006, Web page visited July2, 2009. 